Departamento de Historia

Universidad de Santiago de Chile

Revista de Historia Social

y de las Mentalidades

Volumen 25, $\mathrm{N}^{\circ} 1,2021: 65-110$

Issn Online: 0719-4749

\title{
LAS NEUROSIS EN LA MEDICINA DE BUENOS AIRES (1878-1900): CONCEPTOS, FIGURACIONES Y RESPUESTAS TERAPÉUTICAS*
}

\author{
NEUROSIS IN BUENOS AIRES MEDICINE (1878-1900): \\ CONCEPTS, REPRESENTATIONS AND THERAPEUTIC RESPONSES
}

\author{
DR. MAURO SEBASTIÁN VALLEJO** \\ CONICET \\ Buenos Aires, Argentina \\ Email: maurosvallejo@gmail.com \\ Id-ORCID: 0000-0002-1712-2181
}

\begin{abstract}
RESUMEN
El objetivo de este artículo es analizar el modo en que los médicos de Buenos Aires describieron a fines del siglo XIX las afecciones nerviosas que por ese entonces eran colocadas en la categoría de neurosis.

Se deja constancia de un primer período, durante

el cual las enfermedades neuróticas carecían de autonomía mórbida. Luego, hacia 1890, se difunden concepciones según las cuales esas dolencias eran consecuencia de la vida agitada de las ciudades, y al mismo tiempo se les atribuye una entidad patológica

más definida y segura. Por último, se ensaya una explicación del motivo por el cual el diagnóstico de neurosis fue escasamente utilizado en dispositivos clínicos públicos, en contraste con lo que sucedía en emprendimientos de naturaleza privada.
\end{abstract}

Palabras clave: Neurosis; neurastenia; locura; mercado

\begin{abstract}
The purpose of this article is to analyze how Buenos Aires physicians described at the end of the 19th century the nervous affections that at that time were named neurosis. A first period observes, during which neurotic diseases lacked morbid autonomy. Then, around 1890, explanations according to which these ailments were a consequence of the hectic life of modern cities gained acceptance. At the same time, those ailments received a more defined pathological entity. Finally, an interpretation of why the diagnosis of neurosis was scarcely used in public clinical devices is tested, in contrast to what happened in private enterprises.
\end{abstract}

Keywords: Neurosis; Neurasthenia; Madness; Market

* Recibido: 20 de Marzo de 2020; Aceptado: 7 de Septiembre de 2020.

** El presente artículo fue elaborado en el marco del Proyecto UBACYT 2020 "Neurosios y neurastenia en Buenos Aires: representaciones y terapias entre la medicina y el mercado (18701900)" (cod. 20020190200310BA), con sede en el Instituto de Investigaciones de la Facultad de Psicología de la Universidad de Buenos Aires. BA. 
Cómo citar: Vallejo, Mauro Sebastián. (2021). "Las neurosis en la medicina de Buenos Aires (1878-1900): Conceptos, figuraciones y respuestas terapéuticas”. Revista Historia Social y de las Mentalidades, 25(1), 65-110. https://doi.org/10.35588/rhsm.v25i1.4406

\section{PRESENTACIÓN}

L. S. había luchado durante largos años contra una sífilis rebelde. Cada tres meses debía suspender el tratamiento, pues los preparados mercuriales y el ioduro de potasio destrozaban su estómago. A sus 35 años logró poner fin a aquel tormento, y durante tres años gozó de buena salud. Pero esa bonanza duró poco, pues de inmediato cayó presa de una rara condición. Luego de un catarro estomacal que le hizo perder mucho peso, comenzó a tener hemicráneas seguidas de vómitos incoercibles. El cuadro se completaba con sueño intranquilo, fatiga, irritabilidad y constipación. Con entendible desesperación consultó a los mejores facultativos de Buenos Aires. Uno de ellos diagnosticó una afección cerebral; otro se inclinó por una recidiva del catarro estomacal; un tercer médico confirmó el peor temor de L. S.: quizá se trataba de la reaparición, bajo nuevos ropajes, de su mal sifilítico. Ninguno de los medicamentos indicados surtió efecto. Como último recurso, emprendió un viaje hacia Europa. En el trayecto su estado se tornó aún más desesperante: a una vergonzosa incontinencia de orina se sumó una casi absoluta incapacidad para caminar. En Viena tuvo la fortuna de ser atendido por uno de los neurólogos más afamados, Moritz Rosenthal (18321889), obstinado promotor de la electroterapia en el abordaje de los desarreglos nerviosos. ${ }^{1}$ El médico vienés lanzó sin titubear el diagnóstico que jamás había sido barajado por sus colegas de la capital argentina: L. S. era un típico caso de "neuro-astenia". ${ }^{2}$ Eso sucedía hacia 1882 o 1883, en un momento en que los médicos de Buenos Aires, según parece, no se habían habituado aún a echar mano de ese rótulo tan moderno. L.S. tuvo el extraño privilegio de ser el primer neurasténico de las pampas, aunque se vio obligado a hacer un largo viaje para recibir su condecoración patológica.

1 La obra más importante de Rosenthal, Klinik der Nervenkrankenheiten (publicada en 1870), logró una buena acogida a nivel internacional, y en 1877 fue traducida al francés, con un elogioso prólogo de Charcot (Rosenthal, Traité). Un año más tarde fue vertida al español por Ramón Seeret Comin (Rosenthal, Tratado).

2 Rosenthal dedicaba varias páginas de su tratado a la descripción de la neurastenia y su tratamiento (a través de hidroterapia, drogas y electricidad) (Rosenthal, Tratado 460-470). En rigor de verdad, el autor reservaba ese rótulo para las formas depresivas de la irritación espinal, que según su punto de vista eran consecuencia de excesos sexuales, ligados generalmente a la masturbación. 
Con igual seguridad Rosenthal prescribió el tratamiento oportuno. L.S. debía abstenerse de "todo trabajo mental y físico", evitar "toda sociedad, teatro, juego, etc.", y sobre todo comenzar una cura hidroterápica en el instituto de Wilhelm Winternitz, uno de los adalides de ese método terapéutico. Durante seis meses, el paciente argentino fue sometido a los 'semi-baños' (debía sentarse en tinajas en las que el agua le llegaba hasta la altura de la cintura), frotaciones, sesiones de electroterapia y una severa dieta alimenticia. Una vez concluido el tratamiento, su estado de salud era excelente.

El caso de L. S. figura en un escrito publicado por Pedro Roberts, en tres entregas, en la Revista Médico-Quirúrgica (Roberts). ${ }^{3}$ Esas páginas constituyen con toda seguridad la más temprana irrupción de la categoría de neurastenia (o 'neuro-astenia', para recuperar el término del autor) en la literatura galénica porteña. El objetivo de este artículo es analizar los conceptos teóricos y las explicaciones clínicas utilizadas por los médicos de la capital argentina a propósito de las condiciones patológicas que por ese entonces comenzaban a ser englobadas en la categoría de neurosis. Nuestro estudio hará foco en los textos y documentos editados entre $1878 \mathrm{y}$ el fin de siglo. La fecha inicial de ese arco temporal se explica por la publicación del primer volumen de Las neurosis de los hombres célebres de José María Ramos Mejía; nuestra indagación se detiene en el cambio de centuria debido a que en ese entonces se observan deslizamientos muy claros en las herramientas conceptuales y en los dispositivos clínicos empleados por los doctores en su tratamiento de las enfermedades nerviosas leves.

Durante el último cuarto del siglo XIX la medicina occidental acuñó o redefinió entidades diagnósticas que, incluso a pesar de sus diferencias, tenían algunos rasgos en común. Esas nuevas dolencias (neurastenia, neurosismo, histeria traumática, entre otras) daban cuenta de algunas trasformaciones en las grillas explicativas de los médicos interesados en la medicina mental o los padecimientos psicológicos. En primera instancia, implicaban una clara diferenciación respecto del tópico de la locura o la alienación; no solo porque la problemática de la peligrosidad aparecía desdibujada o ausente, sino también porque a los fines de describir esas nuevas condiciones el lenguaje del delirio o el error quedaba desplazado por nuevos términos, como degaste o automatismo (López Piñero; Koppe). En segunda instancia, y en clara consonancia con lo especializó en oftalmología. Tuvo una participación activa en la Asociación Médica Bonaerense a mediados de la década de 1870, y por esos mismos años se desempeñó como redactor de la Revista Médico-Quirúrgica (Souza). 
anterior, se modificaba abruptamente la localización que correspondía a la enfermedad; el manicomio jamás fue adecuado para observar o remediar los malestares de la neurastenia o la debilidad nerviosa. Por el contrario, la rápida proliferación de neuróticos en las grandes ciudades de occidente atizó la emergencia de nuevos dispositivos clínicos, sobre todo sanatorios privados e institutos ambulatorios. ${ }^{4}$ En tercera y última instancia, el reconocimiento de la legitimidad de las enfermedades neuróticas vino a poner fin a una vieja dicotomía, que reconocía solamente dos polos en lo referido a la vida mental: o la salud o la locura (Pietikainen). En las décadas que aquí interesan se asiste a la aceptación de una tercera zona, más bien intermedia, conformada por sujetos que no deliran ni son peligrosos (y que por ende, no precisan la secuestración en un asilo), pero que presentan manifestaciones sintomáticas muchas veces difusas (angustias, malestares gástricos, insomnio, accidentes sexuales, etc.), y que reclamaban ser reconocidos como pacientes.

En las últimas tres décadas la bibliografía histórica acerca de estos tópicos ha sumado trabajos de gran calidad y erudición. Muchas veces desde un enfoque de historia cultural, merced al cual se ha atendido a los múltiples artefactos que ayudaron a la circulación de figuraciones y representaciones sobre esas neurosis (medicina, literatura, prensa general) y a la heterogeneidad de actores que se movilizaron alrededor de esos enfermos (doctores, boticarios, publicistas), esos estudios han insistido en la necesidad de efectuar un examen localizado de la difusión y desarrollo de esa nueva experiencia patológica. ${ }^{5} \mathrm{En}$ tal sentido, en las páginas que siguen documentaremos las particularidades que presentó la circulación de esos tópicos en la medicina de Buenos Aires en el período señalado. De ese modo pretendemos recortar y examinar un territorio que hasta el momento no ha merecido la atención de los estudiosos. De hecho, en claro contraste con las numerosas investigaciones a propósito de la historia de la psiquiatría y de la locura, se nota una clara ausencia de investigaciones acerca del pasado local de los desarreglos nerviosos, sobre todo en lo que concierne al para enfermos nerviosos y mentales a partir de 1850 en Alemania y Austria, los cuales muy pronto fueron elegidos por los pacientes neuróticos de buena posición económica, que recelaban de los dispositivos manicomiales (Shorter). Los ensayos reunidos en el volumen Cultures of Neurasthenia contienen valiosa información a propósito de ese proceso en otros países del Viejo Continente (Gijswijt-Hofstra y Porter). Para una visión de conjunto, véase (Scull).

5 El ya citado volumen Cultures of Neurasthenia contiene un informado balance de los estudios pioneros en ese área temática. El escrito introductorio resume de modo muy elocuente los modos heterógeneos en que se produjo el abordaje de la neurastenia en los distintos países europeos y en Estados Unidos a fines del siglo XIX (Gijswijt-Hofstra). 
momento previo a la llegada del discurso psicoanalítico. ${ }^{6}$ Conviene advertir una excepción en lo que hace a la histeria femenina. En efecto, de modo reciente se han publicado distintas contribuciones acerca de la historia de esa enfermedad en la medicina y la cultura porteñas de fines del siglo XIX. ${ }^{7}$ Por ese motivo, en este artículo la atención recaerá sobre todo en las producciones teóricas y las acciones clínicas referidas a las otras neurosis o enfermedades nerviosas; por motivos obvios, mínimas referencias al pasado de la histeria resultarán inevitables.

El artículo está dividido en tres secciones. En la primera de ellas se documenta el escaso uso del diagnóstico de neurosis entre los médicos porteños de comienzos de la década de 1880; se conjetura asimismo que uno de los motivos por los cuales la noción moderna de neurosis no pudo propagarse entre los profesionales de la ciudad debe ser hallado en el prestigio de una temprana obra de José María Ramos Mejía. En la segunda, se recuperan algunos de las primeros escritos que intentaron describir las afecciones neuróticas, y se establecen ciertas resonancias entre ellas y una nueva literatura médica referida a síntomas menores que muy pronto serán aprehendidos como signos patognomónicos de las primeras. En la tercera sección se atiende a aquellas producciones escritas entre 1886 y 1900 , en las cuales se atribuyó a las neurosis una férrea autonomía mórbida. Junto con subrayar las concepciones que vieron en la nerviosidad un síntoma de vida moderna, se subraya con especial atención la paradoja que parece amenazar a una literatura que, por un lado, indica el carácter extendido de esas dolencias, y por otro, es casi incapaz de ofrecer ilustraciones clínicas de las mismas.

\section{UN PRECURSOR FALLIDO}

Volvamos por un instante al escrito de Pedro Roberts. En esas páginas no solamente se produce el ingreso del término "neurastenia" al vocabulario médico de Buenos Aires, sino que también quedan anticipados algunos de los

6 Entre las principales contribuciones acerca de la historia de la medicina mental en Buenos Aires, cabe referir los trabajos de (Vezzetti, La locura; Stagnaro; Pita; Ablard). En lo que concierne a la difusión argentina del psicoanálisis, véase los textos de (Vezzetti, Freud; Vezzetti, Aventuras; Plotkin; Dagfal).

7 Algunos de esos trabajos se han concentrado en el modo en que el diagnóstico de histeria fue manipulado en procesos judiciales del fuero penal (Ruibal; Di Liscia y Billorou; Ruggiero). Otros, en cambio, han indagado la localización de la histeria en el entrecruzamiento de discursos, como la medicina, la literatura o la gimnasia corporal (Nouzeilles, "Hysteria"; Nouzeilles, "Asesinato"; Scharagrodsky). Por último, otras contribuciones han exhumado las acciones teóricas y prácticas llevadas a cabo por los médicos (Rodríguez; Vallejo). 
rasgos más sobresalientes de esa novedosa experiencia patológica -rasgos que pueden ser aplicados en verdad a todo el espectro de las neurosis modernas-. Subrayemos al menos dos de esos elementos distintivos. Primero, y en claro contraste con lo que podía suceder a propósito de la locura, se trata de una afección caracterizada por síntomas difusos, inconstantes, lo cual dificulta la tarea de circunscribir el origen del mal. En palabras de Roberts, está en cuestión un "estado nervioso aún no bien definido" (Roberts 236). A modo de evidencia, el autor recurre a un segundo historial: el Doctor C., abogado argentino de 38 años, que padecía insomnio, fatiga, dolores de cabeza, alteraciones del estado de ánimo y malas digestiones. Todo aparenta ser movedizo en esa afección; los síntomas cambiantes y borrosos se prestan a la confusión con otras enfermedades, sobre todo del estómago o del cerebro. Lo único que parece constante -y ello ya resulta notorio en la descripción de Roberts- es la presencia de un fondo de debilidad. De manera amorfa todavía, y sin un lenguaje claro, pareciera que el tópico de la energía conforma aquí el hilo rector de la enfermedad:

Los síntomas que predominan (...) son los de depresión general, que se traducen por un batimiento muy grande, como ya hemos visto; existe debilidad, agotamiento de todas las fuerzas, falta de coraje y de disposición para el trabajo físico e intelectual sobre todo; desde que despiertan los enfermos, sienten ese cansancio del cuerpo que es reparado en las personas sanas después del reposo de unas cuantas horas en el lecho. (Roberts 52)

No solo resulta enigmático el origen de ese desarreglo, sino que también constituye una incógnita a qué parcela de la medicina debe ser ligada la afección: en palabras de Roberts, algunos autores la reconducen a un estado gotoso o reumático; de acuerdo con otros diplomados, sería una consecuencia de la anemia; otros, en cambio, ven en ella un modo de presentación alternativo de cierta alteración gástrica. El tenor incierto de la neurosis movió a un joven médico local a decir que las afecciones englobadas en esa categoría eran "entidades mórbidas que forman, por decirlo así, el cortejo metafísico de la patología, tan grande es la oscuridad que reina sobre su etiología y patogénesis" (Echenique 7). Unos años atrás, un colega que había participado de la fundación del Círculo Médico Argentino, y que se mostraba muy disconforme con las viejas concepciones médicas, edificadas con más imaginación que conocimiento positivo, lamentaba que fuera habitual "amalgamar, al punto de confundir, bajo los nombres de vapores o enfermedades nerviosas, afecciones enteramente diferentes" (Mendioros 12). 
El segundo elemento a remarcar puede ser desglosado del modo que sigue. La irrupción de las enfermedades nerviosas marca el ingreso de un nuevo sujeto a la medicina mental. No es posible construir estadísticas a partir de dos casos. Pero no podemos ocultar que en los dos historiales presentados por Roberts en su escrito inaugural, queda plasmada la imagen prototípica del nuevo enfermo neurótico. En la presentación en sociedad de esta nueva especie patológica, L. S., un hombre que "conoce el mundo" y que puede darse algunos lujos, comparte escena con el Dr. C., un abogado que ha caído en las garras del mismo mal. Estamos muy lejos del perfil emblemático del loco porteño, definido de forma duradera por Lucio Meléndez y Emilio Coni en su célebre ensayo estadístico de 1880 sobre los alienados ingresados al manicomio porteño en las dos décadas anteriores: allí los albañiles, zapateros, labradores y carpinteros formaban una inmensa mayoría, que encima solía entenderse en italiano y entregarse a los excesos del alcohol (Meléndez y Coni 517-518). El nuevo enfermo mental, menos peligroso pero más sombrío, suele ser un sujeto culto, bien educado, que asiste al teatro o que lee novelas a la moda. No es ya el habitante de los márgenes urbanos, ni el estandarte de esa amenaza llamada degeneración; es, por el contrario, el prójimo más cercano, el habitante promedio de los barrios codiciados de la ciudad. ${ }^{8}$

Otras fuentes parecen confirmar las opiniones de médicos como Mendioros o Echenique, quienes señalaron la confusión que reinaba en la medicina porteña de inicios de la década de 1880 a propósito de las afecciones nerviosas no psicóticas. Y esas mismas fuentes revalidan asimismo la conclusión que cabe extraer del historial de L. S. presentado por Roberts: era casi imposible que un médico local empleara por esos años el diagnóstico de neurastenia en su trabajo clínico cotidiano. Cabe citar, a ese respecto, dos fuentes relativamente similares. Por un lado, un escrito de 1880 del principal alienista de la ciudad, Lucio Meléndez, en el cual se registran los detalles de la enfermedad que aquejó a N., un sacerdote español de 39 años. Hacia 1878, luego de una caminata de unas doce cuadras, N. "tomó un baño tibio sin tener la precaución de mojarse la cabeza con agua fría" (Meléndez, "Clínica" 78). De inmediato comenzó su calvario: ansiedad, opresión, mareos y dificultad para sostenerse en pie. Como los síntomas no desaparecían, consultó a un médico, que tras revisarlo "le dijo que no tenía nada". Visitó luego a cinco facultativos distintos; algunos de ellos se ruborizó cuando en 1898 se barajó el diagnóstico de neurastenia para explicar la debilidad nerviosa y los malestares corporales del expresidente Carlos Pellegrini -quien, desandando los pasos de L.S., se dirigió a París para buscar alivio en una Maison d'hydrothérapie (Groussac 254). 
dijeron que no comprendían cuál era el mal que lo aquejaba; Ayerza (padre), por su parte, "le dijo categóricamente que no tenía nada" (79). A los viejos malestares se sumaron otros igual de molestos: no podía retener nada en la memoria, era incapaz de escribir, le era imposible concentrarse o prestar atención. Esa progresión patológica no hacía sino alimentar su rencor hacia los diplomados: "Se le decía que no tenía nada y su carácter, el que se había vuelto irascible, y su sistema nervioso periférico y central se encontraban tan irritados que al menor choque contra su cuerpo o un grito dado próximo a él le excitaban sobremanera" (Meléndez, "Clínica" 79). Cuando finalmente fue a ver a Méléndez, hacia fines de 1879, el alienista diagnosticó una "congestión cerebral activa en el período crónico", y prescribió bromuro de potasio, purgantes y un leve sangrado. El tratamiento se mostró eficaz, y muy pronto el clérigo pudo retomar su vida normal.

El segundo escrito a recuperar es el historial incluido por Juan Mateo Franceschi en una nota publicada en 1885 en la Revista Médico-Quirúrgica (Franceschi). El artículo tenía el objetivo de denunciar el mal hábito de ciertos médicos de renombre de la Capital Federal, que al ser consultados por enfermos desahuciados del interior, eran incapaces de ahuyentar los temores de sus clientes, a quienes despedían con palabras de desesperanza. Este enfermo en particular, oriundo de Chivilcoy, padecía "trastornos nerviosos" que se manifestaban por palpitaciones, sofocación, insomnio y dispepsia. Se dirigió a la ciudad de Buenos Aires, donde uno de aquellos diplomados de dudoso prestigio lo despachó con un diagnóstico de pronta muerte. El pobre nervioso volvió a su casa y se pegó un tiro, pero la herida no fue mortal; a resultas del disparo, perdió la mandíbula y la lengua. Sus malestares nerviosos desaparecieron, pero quedó condenado a alimentarse a través de un embudo.

A pesar de que las conjeturas contrafácticas deben ser manejadas con precaución, resulta inevitable presumir que una década más tarde, el enfermo $\mathrm{N}$. o el habitante de Chivilcoy seguramente hubiesen sido tildados de neurasténicos por cualquier médico porteño más o menos informado. Para 1880 (o incluso para mediados de esa década) enfermos de estas características -que no tenían los recursos para tomar un barco hacia Viena- debían conformarse con un enfático "no tiene nada", o bien con una terminante sentencia de muerte.

No ha de sorprender que las cosas sucedieran de ese modo. La neurosis en sentido moderno era una conquista reciente de la medicina occidental. Si bien el término tenía una historia más larga, tal y como recordaremos más abajo, su significación moderna databa de los inicios del último tercio de la centuria. Recién en las décadas de 1860 o en la siguiente, autores como Georges Beard en Estados Unidos o Eugène Bouchut en Francia dieron forma a las definiciones que habrían 
de perdurar largas décadas, y que muy pronto ganaron extensa popularidad en la literatura científica y en las tramas culturales en sentido general. Esas nuevas concepciones fueron las responsables de que se asignara al concepto de neurosis un sentido más restringido (enfermedades nerviosas no psicóticas, caracterizadas por manifestaciones corporales, psicológicas y afectivas), y que por lo tanto se legitimara la existencia de esos nuevos enfermos que ponto fueron tildados de neurasténicos, nerviosos o histéricos. La autonomización del campo neurótico resultó no solamente de nuevos conceptos en la medicina mental, sino también de la emergencia de dispositivos clínicos que podían alojar la nueva experiencia patológica (institutos ambulatorios de hidroterapia, electroterapia, etc.)

Por lo antedicho, resulta comprensible que la llegada y difusión de esas representaciones a propósito de las neurosis no fueran en Buenos Aires procesos espontáneos o transparentes. Las nuevas figuraciones teóricas, y los ensayos terapéuticos que pudieran afrontar esa experiencia patológica, llegaron a una cultura médica en que los lenguajes fisiológicos que prevalecían en el Viejo Continente tenían aún un escaso desarrollo, y en que los dispositivos clínicos eran muy distintos a los de ultramar.

A los fines de ilustrar la particular recepción del vocabulario de las neurosis en la capital argentina, es menester hacer algo más que documentar la imposibilidad en que los doctores se hallaban, al menos hasta fines de la década de 1880, para apelar a diagnósticos como el de neurastenia. En aras de comprender mejor esa singular mediación receptiva, debemos dirigir la mirada a la obra teórica que por esos años ganó un seguro renombre en ese terreno científico. Nos referimos a Las neurosis de los hombres célebres en la historia argentina, publicada por José María Ramos Mejía en dos tomos en 1878 y 1882. En efecto, ese libro fue el primero en utilizar de modo sistemático el concepto de neurosis en la literatura científica local, y las definiciones que a ese propósito desplegó tuvieron un fuerte impacto en el discurso galénico hasta al menos el cambio de siglo. El valor de la contribución de Ramos Mejía no resultó solamente del contenido interno de la obra, sino que fue fortalecido a posteriori por las posiciones que su autor ocupó en el proceso de conformación de un estudio local sobre lo nervioso. En efecto, en 1885 Ramos fue colocado al frente de la primera sala hospitalaria especializada en enfermedades nerviosas (en el Hospital San Roque), y dos años más tarde fue designado profesor titular en la recién creada cátedra homónima (Cantón).

No podremos realizar en esta oportunidad un análisis detenido de esa obra. Recordemos simplemente que su finalidad era mostrar, a través del examen de cinco figuras emblemáticas del pasado político local (Rosas, Monteagudo, Dr. Francia, Almirante Brown y Fraile Aldao), cuán determinantes podían ser 
las enfermedades nerviosas de los líderes en el destino de un pueblo. El libro de Ramos fue el artífice de un efecto paradójico, debido a que, por un lado, popularizó y legitimó la categoría de neurosis en la ciencia de lo mental, pero por otro, apeló para ello a una definición vetusta del concepto, que muy pronto quedaría en desuso en el discurso profesional. En efecto, retomando el proyecto y las definiciones forjadas por Philippe Pinel a comienzos de siglo, Ramos entendió por neurosis toda afección mental caracterizada de manera negativa por falta de fiebre y ausencia de lesión orgánica (López Piñero 45-47). A resultas de esos presupuestos, las neurosis incluían a la epilepsia, las neuralgias, las coreas, la manía, la melancolía, y sobre todo a las vesanias (locuras delirantes).

Las locuras, con su compromiso de las facultades intelectuales y sus múltiples graduaciones (desde la extravagancia apenas perceptible hasta el furor delirante), formaban según Ramos el sector más importante y valioso de las neurosis. ${ }^{9}$ En términos estrictos, el neurótico era para Ramos aquel sujeto que padece un estado intermedio; delira, pero solo sobre algunos objetos, logrando el resto del tiempo conservar la apariencia de la razón. El neurótico, para retomar las palabras de su autor, no estaba en "el goce pleno de sus facultades", pero tampoco merecía el encierro en el manicomio (Ramos Mejía, Las neurosis 24). Era un "ser híbrido", un "mestizo intelectual", que resiste cuanto puede la explosión del delirio que, tarde o temprano, tomará posesión de su cabeza. Más allá de las imprecisiones que gobiernan el vocabulario del joven Ramos, hay dos doctrinas que le permiten fundar la existencia de este extraño grupo, y que le posibilitan explicar la proliferación de sus neuróticos a lo largo del tiempo: el organicismo (más particularmente el localizacionismo cerebral) y el hereditarismo. ${ }^{10}$

Lejos de quedar definida como el resto o el envés de la enfermedad mental delirante, tal y como ya venía sucediendo en la ciencia europea (y tal y como sería pronto replicado en Buenos Aires), la neurosis toma en el libro de 1878 la forma de la puesta al extremo de la locura. A tono con teorías de ultramar que por ese entonces comienzan a ser abandonadas, antes que una entidad que médico, reside el motivo por el cual Ramos se negó de modo obstinado a reeditar su primer libro (Ingenieros 112). Sus discípulos más cercanos no dejarán de denunciar, luego de la muerte de Ramos Mejía, y en ocasión de la reedición de sus primeras obras, el carácter equivocado u obsoleto de la categoría de "neurosis" empleada por el maestro en 1878. La crítica más inclemente contra ese concepto fue enunciada por Francisco de Veyga (De Veyga, "Prólogo" XX-XXIII).

10 El localizacionismo, incluso de tenor frenológico, tenía muchos adeptos entre los médicos locales de esos años. Tanto es así que un temprano y entusiasta comentador de la obra de Ramos dictaminó que el libro de 1878 era la "primera manifestación científica de la frenología moderna” (Millán 207) 
cuestione el protagonismo del delirio en el territorio de las afecciones nerviosas, la neurosis de Ramos es un nuevo modo, menos visible pero más disgregante, del delirar. El neurótico de Ramos, con Rosas a la cabeza, es aquel loco capaz de llevar una vida ordenada y pulcra, pero que dentro de sí esconde el germen de un desequilibrio que cualquier accidente puede activar.

La obra de juventud de Ramos reclama aún otros dos comentarios. El primero de ellos apunta también al modo en que este médico prestó un auxilio paradójico, si no contraproducente, en el incipiente discurso local sobre las neurosis. Tal y como ya se dejaba entrever en el texto de Roberts, y como se reforzaría en intervenciones posteriores, la nueva mirada médica sobre la neurosis estaba basada en la presunción de que esos nuevos pacientes nerviosos eran sujetos tan cultos y honrados como los médicos que los atendían. Enfermedad no significaba ya otredad peligrosa. Pues bien, Ramos permaneció inmune a ese desplazamiento. Amparado en su perspectiva, merced a la cual el acento era puesto en la heredabilidad y la latente peligrosidad de estas enfermedades nerviosas, Ramos seguía viendo en la neurosis un sinónimo de ajenidad y distanciamiento. Los neuróticos emblemáticos de Ramos no eran el vecino decente y cercano, sino el caudillo excepcional y enceguecido por su delirio.

El segundo comentario tiene que ver con una ligera innovación que Ramos introduce en su ideario entre la publicación del primer volumen y el segundo. En efecto, el tomo dos, editado en 1882, se cierra con un breve capítulo titulado "Las pequeñas neurosis". Allí parecen producirse tímidos deslizamientos hacia un dominio que no queda, empero, nítidamente precisado, y que a cada instante corre el peligro de ser fagocitado por el marco argumentativo tradicional. Esas páginas de cierre permanecen atrapadas en una tensión irresuelta entre, por un lado, la proyección de una figura novedosa que nunca termina de ser plasmada, y por otro lado, la recuperación de la figura de neurosis que ha primado desde el primer volumen, en la cual el delirio parcial latente, agazapado en la mente de alguien que por lo demás lleva una vida meticulosa, tarde o temprano emergerá.

En palabras de Ramos: "Muchas veces vivimos una vida entera con un individuo, admirando el vigoroso equilibrio de su cerebro, hasta que un día, el más inesperado por cierto, ponemos la mano sobre la nota falsa que lanza el chillido característico, revelando la abolladura" (Ramos Mejía, Las neurosis 211). Están comprendidos allí el hombre culto pero feo, que de pronto se cree amado y acosado por todas las mujeres; el profesional juicioso, que sin embargo en su fuero interno se cree un pintor eximio; o el comerciante sensato, que perdía la cabeza cada vez que caía en la idea de ser un excelente mecánico. En todos ellos una idea falsa amenaza de modo constante con invadir íntegramente la vida mental, produciendo lamentables extravagancias. Ahora bien, por otro 
lado, Ramos Mejía dibuja un segundo perfil de esas pequeñas neurosis, donde el elemento rector no es ya la creencia desviada o la idea falsa, sino más bien un oscuro afecto o sensación. Los ejemplos aquí son: el irracional temor a los truenos que padecían Lamadrid y el general Alvarado, el miedo a la oscuridad de Olavarría, la hipocondría de Lafinur, y sobre todo la agorafobia. Estamos, por tanto, ante una doble alteración: a nivel más visible, abultan el conjunto de esas pequeñas neurosis estados apenas patológicos, que no habían quedado dibujados en el tomo primero de 1878, y que estaban caracterizados más por sensaciones (o afectos) que por delirios parciales. Por debajo de esa cohibida innovación, se anuncia otra, quizá tanto o más significativa. Ramos concede que cualquiera, incluso el lector más culto, puede verse aquejado por esas condiciones patológicas. En las líneas que cierran la obra, afirma: "Estas son las pequeñas neurosis. Ahora completad el estudio en vos mismo, lector curioso, si acaso habéis sentido alguna vez rozar por vuestro cerebro algunas de esas mariposas negras del pensamiento" (Ramos Mejía, Las neurosis 228). Esa sentencia no era otra cosa que la invitación que el autor lanzaba a sus semejantes (y a sí mismo) a reconocerse como pequeños y nada célebres neuróticos.

Quizá la adición de esas pequeñas neurosis fue el modo en que Ramos Mejía buscó solucionar lo irresoluble: con ellas quiso incorporar a su obra las figuras patológicas que ya comenzaban a rondar la ciudad de Buenos Aires; quiso que su propuesta también valiera para esos nuevos enfermos que, con sus temores y sensaciones accidentadas, nada tenían que ver con los locos. Pero esas páginas finales no podían tapar el sol con la mano: casi en el instante en que, gracias al auxilio de términos como neuro-astenia o nerviosidad, lo neurótico clamaba por ser reconocido como un novedoso capítulo de la patología nerviosa, Ramos Mejía buscó su lograda celebridad con una obra que, a nivel al menos de su lenguaje psicopatológico, envejeció antes de nacer.

La obra de juventud de Ramos podía prestar una ayuda asaz problemática a la recepción local de discursos y grillas interpretativas de las neurosis en un sentido más moderno. Su organicismo, su insistencia en el elemento delirante, su fidelidad a una significación tradicional (si no envejecida) del concepto de neurosis, eran elementos que, sin ir más lejos, imposibilitaban que los nuevos enfermos nerviosos que aparecían en la ciudad (como por ejemplo L. S.) se reconocieran en el libro que hizo célebre a Ramos en los ambientes científicos de Buenos Aires. A ello hay que sumar que las otras iniciativas desplegadas por este médico porteño tampoco funcionaron como plataformas ideales de difusión de concepciones modernas de lo neurótico. Ello vale sobre todo para 
su labor al frente de la materia "Enfermedades nerviosas" a partir de $1887 .{ }^{11}$ Cuando se decidió crear esa cátedra, el objetivo esencial era posibilitar el estudio y la enseñanza de todas aquellas experiencias patológicas que, teniendo asimismo manifestaciones en la esfera de lo mental, no pudieran ser abarcadas en la ya existente materia "Enfermedades mentales", a cargo del alienista Lucio Meléndez. Según la documentación y los testimonios disponibles, lo que sucedió efectivamente fue lo siguiente. Por un lado, si bien esa cátedra alentó el estudio de patologías neurológicas con claro basamento orgánico (como las parálisis generales, la meningitis o la esclerosis en placas), Ramos de alguna forma se desentendió de esas materias, que no concitaban su interés. Dejó esos asuntos estrictamente neurológicos en manos de algunos de sus colaboradores. ${ }^{12}$ Por otro lado, su verdadero entusiasmo recayó en la prosecución de un proyecto iniciado con su libro de 1878, cuya meta era reflexionar sobre rostros alternativos de la locura (sobre todo esas formas de locura que a primera vista no resultan estridentes, y que pueden ser confundidas con la normalidad). Uno de sus discípulos más cercanos lo confesó sin ambages varias décadas más tarde:

Lo que fue esa cátedra y lo que fue esa enseñanza, lo sabemos todos los que fuimos alumnos suyos o colegas en el curso del largo desempeño. Aceptado un poco a la fuerza este nombramiento después de tantas renuncias y comunicaciones, el flamante profesor, todo fuego en un principio, fue perdiendo poco a poco sus entusiasmos iniciales para concretarse al final al solo cumplimiento de sus obligaciones escolares.

11 Lamentablemente han quedado muy pocos rastros de la labor de Ramos al frente del servicio de "Enfermedades nerviosas" del Hospital San Roque. Artículos y tesis de discípulos atestiguan que allí, siempre gracias a la dirección de auxiliares del jefe de sala, efectivamente se llevó adelante un estudio sistemático de variadas patologías neurológicas graves.

12 A ese propósito, resulta muy elocuente el testimonio de un sujeto que cursó la materia poco después de su creación (Aráoz Alfaro 212-213). Otros documentos insisten en el desgano que rápidamente se apoderó de Ramos en su trabajo universitario (Ingenieros 113-114). Por otro lado, diversas fuentes indican que, fuere por ese desgano o fuere por sus múltiples ocupaciones (sobre todo en el ámbito de la política o de la gestión gubernamental), Ramos Mejía faltaba a muchas de las lecciones que debía impartir; por ejemplo, en un cuadro referido al movimiento de las aulas de la facultad de medicina durante 1889, Ramos Mejía fue uno de los docentes con más inasistencias (37) (Memoria de la Facultad de Ciencias Médicas 72). Esa inconducta no pasó desapercibida para las autoridades, quienes reprendieron al docente. Por ejemplo, en su legajo académico se conserva una nota del 2 de mayo de 1890, en la cual el Consejo Superior solicitaba al decano de Medicina (González Catán) apercibiera a Ramos por haber faltado de modo reiterado, y sin causa justificativa, a sus lecciones; ver Legajo 5793, "José María Ramos Mejía”, Archivo de la Facultad de Medicina de la Universidad de Buenos Aires, f. 18. 
El estudio de la patología mental lo atraía en cambio cada vez más; esa era su vocación. Esta rama médica fue, en efecto, como lo dijera desde un principio y como lo manifestara prácticamente en sus primeros trabajos científicos, sus 'Neurosis' especialmente, su gran devoción, mantenida durante el curso entero de su vida. Puede decirse que nunca hizo cátedra de patología nerviosa. Las magistrales lecciones de clase publicadas por él en 1893, versan todas sobre asuntos de patología mental, ninguna sobre asuntos relativos a la neuropatología. (De Veyga, "Conferencia" 63)

Este último comentario del discípulo merece ser remarcado. En 1893 Ramos publicó Estudios clínicos sobre las enfermedades nerviosas y mentales, un volumen que contenía lo más sustancial de su enseñanza universitaria. Pues bien, De Veyga está en lo cierto al afirmar que parece más un libro de psiquiatría que de enfermedades nerviosas. Ello no quiere decir, por supuesto, que en otras producciones teóricas no se haya referido a las neurosis, como por ejemplo a la histeria o la neurastenia. En cada ocasión en que teorizó acerca de esas patologías neuróticas, recuperó la perspectiva que había atravesado su libro de 1878; es decir, incluso para fines de siglo Ramos aprehendió en las neurosis condiciones que no se diferenciaban demasiado de las locuras delirantes; a lo sumo, las primeras debían ser definidas como los anticipos de aquellas enfermedades más preocupantes. ${ }^{13}$

\section{HACIA LA AUTONOMÍA MÓRBIDA}

Hemos intentado mostrar que el proyecto intelectual y profesional de Ramos Mejía no podía sentar las bases para una recepción facilitada de los tópicos y conceptos que en otros contextos médicos aseguraron el reconocimiento de las neurosis como condiciones patológicas legítimas y autónomas. Por otro lado, es posible mostrar que otros médicos porteños, que también poseían cierto prestigio en el terreno de lo nervioso, abrigaban concepciones bastante similares a las de Ramos. Ello sucede, por ejemplo, con Inocencio Torino, autor de uno de los primeros trabajos locales sobre el funcionamiento automático o inconsciente de los procesos nerviosos (Torino, Estudio). En una conferencia dictada en la Facultad de Medicina en 1885, titulada "Las neurosis", este diplomado llegó

13 Ello es evidente en La locura en la historia, de 1895, en donde observamos una indistinción entre histeria y alienación delirante (Ramos, La locura 407-467). 
a conclusiones muy similares a las del autor antes estudiado. En efecto, el primer elemento que según Torino singulariza "al vasto y misterioso campo de las neurosis, tan variadas, tan singulares, tan llenas de secretos", tiene que ver con un aspecto negativo: la ausencia de causa orgánica ostensible (Torino, "Las neurosis" 52). Las neurosis (clasificables en neurosis de la inteligencia, de la sensibilidad y del movimiento) encuentran su esencia en aquello que les falta, en aquello que las diferencia de enfermedades de fronteras y rasgos mejor delimitables, dependientes de desarreglos materiales de los centros nerviosos. El segundo elemento que ayuda a trazar su perfil alude, una vez más, a otra forma de la negatividad: la simulación. Torino recuerda que las neurosis se caracterizan por emular, sin la intervención de lo mental -es decir, sin que corresponda hablar de intención del paciente, o de un saber sobre lo que reproduce-, muchas enfermedades orgánicas, sobre todo de naturaleza febril.

Luego de asentadas esas dos proposiciones, y después de admitir que no considera relevante la descripción de la sintomatología, Torino dedica el grueso de su conferencia a examinar "un punto que afecta todas las neurosis y domina casi toda su historia: me refiero a la etiología y dentro de ésta al papel importante que en ella desempeña un factor de consideración en la vida universal: la herencia" (Torino, "Las neurosis" 57). Dada la infinita variedad de las manifestaciones sintomáticas, y dado asimismo el carácter endeble de la presunción sobre la ausencia de fuente material, Torino encuentra en la herencia el único elemento capaz de trazar un perfil seguro de las neurosis, sobre todo porque permite comprender los porosos límites internos que sectorizan ese grupo de patologías. En efecto, la herencia de transformación, bajo la forma de la teoría de la familia neuropática, explica sin fisuras la evolución de estos desarreglos: los "lazos filogenéticos" que dejan amarrados entre sí a los contados rostros de la neurosis. Dicho en otros términos, no es casualidad que un padre coreico tenga hijos histéricos, o que un epiléptico traiga al mundo vesánicos o criminales. Esas alternancias que la herencia pone de manifiesto, no hacen sino develar "un fondo común, en el cual se funden todas esas modalidades del neurosismo" (Torino, "Las neurosis" 57). No cabe desatender que entre esas "modalidades del neurosismo" se incluyen, junto a la histeria o la hipocondría, la locura (o vesania), la criminalidad o el idiotismo. ${ }^{14}$ La herencia no hace más que evidenciar su "parentesco, la identidad casi de todos esos estados" (57). Distinguirlas es algo artificial, pues en verdad se trata de una entidad mórbida única, y su estudio

14 Ya en un escrito pericial del año anterior, Torino inclúa el delirio epiléptico entre las "grandes neurosis" (Torino, "Estado mental"). 
no debe ser encaminado sino hacia el examen de su mecanismo propagador. Estudiar las neurosis es, a fin de cuentas, atender a la raza. E intentar curarlas es un despropósito, pues para ello sería necesario suprimir la herencia.

En el caso de Torino, el costo del repliegue o el opacamiento de lo neurótico no es tanto su confusión con el tópico tradicional del delirio, sino más bien su disolución (y el potencial borramiento de sus tabiques internos) en el pavor de lo hereditario. El segundo parecido con Ramos está dado por la desconexión entre lo neurótico y la posibilidad de un tratamiento. En el cierre de su escrito, Torino concluía: "No curaremos tal vez - ¡no importa!” (Torino, "Las neurosis" 59). Esa afirmación parece una mera extensión de uno de los enunciados colocados por Ramos a propósito de las "pequeñas neurosis" en el cierre de su segundo volumen: "Esos estados de ánimo son incurables" (Ramos, Las neurosis 224). Tal y como comprobaremos más adelante, el progresivo arraigo de la experiencia neurótica en la ciudad fue de la mano de la construcción de un mercado terapéutico que le hiciera frente. Y es por ello sintomático que los autores que no fueron capaces de reconocer la autonomía mórbida de esas afecciones hayan desestimado sin más la posibilidad de su cura.

Por esos mismos años, sin embargo, otros médicos comenzaron a difundir concepciones alternativas sobre lo nervioso. Ellas, al igual que las páginas de Roberts, trazaban del sujeto nervioso un perfil muy distinto al bosquejado por Ramos o Torino. Sobre todo porque en su mayoría tendieron a reafirmar, mediante conceptos de talante 'neurológico', las imágenes e idearios (ligados al desgaste, la sobreexcitación o la cuasi normalidad) que poco a poco tiñeron la esencia de la nueva condición. Citemos, por ejemplo, la tesis de Carlos Díaz, El nervosismo, defendida en 1883. Basándose en las teorías de Eugène Bouchut (sobre todo su tratado De l'état nerveux aigu et chronique ou nervosisme, de 1860), Díaz entendía que el nervosismo era "una neurosis general, caracterizada por alteraciones funcionales de la sensibilidad, la inteligencia, la motilidad y de los órganos internos", que debía ser diferenciada de las dos neurosis más célebres (la histeria y la hipocondría), pero que claramente se correspondía con afecciones ya descritas, como la irritación espinal o la "debilidad irritable de los Ingleses" (Díaz 15-18). ${ }^{15}$

En términos generales, proseguía el médico porteño, es posible distinguir el nervosismo primitivo, caracterizado por la falta de lesiones orgánicas, del secundario, desarrollado como efecto simpático de una alteración en otros órganos, sobre todo los digestivos (dispepsia). Más allá de esa distinción, Díaz

15 El término de Bouchut ya había sido recuperado, de modo ciertamente problemático, por Samuel Gache en un texto anterior, en el cual primaba acerca de la patología mental o nerviosa una visión muy similar a la que Ramos Mejía había plasmado en su obra de juventud (Gache, "El estado" 614). 
enfatizaba un elemento que reaparecerá en otras producciones galénicas del período: el hecho de que el nervosismo "se declara en individuos perfectamente sanos y vigorosos" (Díaz 19). Si bien ese comentario buscaba distanciar esta patología de diátesis ostensibles como la clorosis, lo que de alguna forma certifica es la naturaleza cuasi-patológica de la afección, y por ende la injusticia de hacerla equivaler con la otredad. A diferencia del loco, e incluso a diferencia de la víctima de cualquier otra enfermedad, el sujeto aquejado de nervosismo es, hasta cierto punto, un sujeto a simple vista normal; su condición apenas puede ser tildada de enfermedad, no solo por el vigor que aparenta su portador, sino por la naturaleza difusa de los síntomas que lo aquejan (temblores, eretismo nervioso, espasmos musculares, insomnio, dolores vagos, palpitaciones, constipación, irascibilidad, fotofobia):

Podría admitirse a priori que la enfermedad es grave, si consideramos que una vez iniciada constituye un padecimiento de larga y casi indefinida duración. Produce insignificantes molestias, muchas veces, pero que bastan para perturbar el estado fisiológico, constituyendo una ligera enfermedad. (...) Un sufrimiento más o menos compatible con la vida, ésta es la enfermedad. (Díaz 76)

Esa naturaleza cuasi-patológica aparece quizá con mayor nitidez en un escrito que revisaremos más abajo:

El que empieza a sentirse falto de sueño, abatido y cansado, quien no llena sino con esfuerzo las tareas de su profesión u oficio, quien se irrita y altera por las leves contrariedades de la vida diaria, quien sufre dolor de cabeza, fluxiones de sangre, latidos del corazón, opresión, es un enfermo nervioso y necesita restablecerse urgentemente". (Susviela Guarch 434)

Eseseñalamientonospermite conjeturarque en realidadlaproblematización galénica sobre el neurosismo (y luego la neurastenia) formó parte de un proceso más vasto, consistente en la pretensión de la disciplina médica de apropiarse, merced a una siempre desmañada patologización, de condiciones que se parecían poco a las enfermedades clásicas, y mucho a avatares molestos de la normalidad. Esas patologías neuróticas eran, según uno de los autores que se ocuparon de ellas, "enfermedades benignas" (Alurralde 11). En efecto, por esos mismos años podemos notar el interés teórico y práctico de los médicos por signos, defectos y molestias de la vida cotidiana, que poco a poco comenzarán a ser englobados 
como síntomas y rasgos característicos de estas nuevas patologías nerviosas, como por la jaqueca, el insomnio o los problemas digestivos (dispepsia). En esta ocasión podemos ocuparnos de esas dos últimas condiciones, pues ellas concitaron un relativo interés de parte de los médicos porteños.

Respecto del trastorno del sueño, cabe recuperar la tesis defendida en 1880 por Guillermo Achával. Estamos ante un trabajo erudito, con sobradas pretensiones teóricas, y que de hecho contiene una informada reseña de todo lo que la medicina continental había investigado hasta ese entonces a propósito del funcionamiento nervioso reflejo y de la fisiología del sueño. Lo más destacado, empero, no reside en el uso que Achával hace de un lenguaje de la sobreexcitación nerviosa, sino en un elemento que se halla en sintonía con otras fuentes que revisamos aquí. La ponderación de las explicaciones propuestas para describir el insomnio, y de las terapias recomendadas para combatirlo, la realiza el autor en base al examen del caso que mejor conoce: él mismo. En efecto, Achával había sido víctima, durante seis años, de una pertinaz incapacidad para dormir, y la tesis contiene el desglose pormenorizado de esa confidencia patológica (Achával 87-97). Si el primer neuro-asténico del paisaje sanitario porteño fue L. S, aquel viajero acaudalado, el primer insomne fue Guillermo de Achával, futuro diputado nacional y catedrático de la Universidad. Otros médicos seguirán su ejemplo; la narración de muchos síntomas neuróticos se confundió en Buenos Aires con el relato autobiográfico de los diplomados. Con ello certificaban que esta nueva experiencia mórbida, amén de afectar a sujetos que no eran ni peligrosos ni incapaces, no tenía nada que ver con esa otredad degradante que Torino o Ramos denunciaban en vano.

Los malestares intestinales, quizá el síntoma más seguro y repetido consignado en los escritos sobre neurosismo o neurastenia, tuvieron una presencia mucho más marcada en la literatura galénica de esas décadas. En un escrito de diciembre de 1883, el médico de origen español Silverio Domínguez señalaba el fundamento nervioso de muchos cuadros de diarrea de los porteños, "una modalidad de la que poco se ha escrito" (Domínguez 196). De todas maneras, la condición más estudiada por esos años fue la dispepsia, que fue objeto de numerosas tesis de grado durante el último cuarto de siglo. Importa señalar, entre otras cosas, que el trabajo más temprano, debido a Lorenzo Martínez, contiene de alguna forma una toma de conciencia de la ardua tarea que suponía patologizar, o llevar al redil del lenguaje médico, una problemática que parecía prestarse muy mal a ese cometido, por su condición vaga y su presentación clínica multiforme. A tal respecto, el joven médico reclamaba: la "palabra dispepsia tiene que desaparecer forzosamente del vocabulario nosológico, porque es un término vago que no significa más que la dificultad de la digestión" (L. Martínez 7).

Sin embargo, el sendero elegido por la medicina iba en una dirección 
contraria, y lo que primó fue el esfuerzo por definir la entidad patológica aun a pesar de su presunta vaguedad o de su extensión desmedida. Así, en una tesis presentada poco después, Virgilio Moyano afirmó que "La dispepsia es una enfermedad tan general que la mayoría de las personas la padecen" (Moyano 9). En igual sentido, en un trabajo redactado unos años más tarde se defendía la necesidad de estudiar de cerca esa afección tan prevalente, "que afecta próximamente el $80 \%$ de la población total" (Gallastegui 12). Ese balance desmedido iba acompañado, sin embargo, de la confesión de que la medicina aún no funcionaba como plataforma de alojamiento y recepción de una condición cotidiana, que los sujetos podían resolver por otros medios: "el número de casos observados no ha llegado a la altura de mi deseo, y porque la dispepsia que no es enfermedad de Hospital, sólo lleva por accidente algún individuo en este estado a esos establecimientos públicos de caridad" (Gallastegui 19). Lo más valioso, sin embargo, se halla en el hecho de que en esas páginas sobre la dispepsia, que ya por entonces era reconocida como el síntoma casi universal de los padecimientos nerviosos, cobró forma una prematura lamentación sobre las costumbres malsanas de la ciudad moderna, sobre todo su cariz debilitante (Gallastegui 27). ${ }^{16}$ Más abajo documentaremos que en esos mismos años la literatura sobre el neurosismo o la nerviosidad fue inseparable, tanto en el contexto local como en el extranjero, de una narración de las consecuencias indeseadas de la modernidad (la aceleración, la sobreestimulación, la proliferación de placeres artificiales, etc.).

Dado que, tal y como veremos en unos instantes, el vocabulario del desgaste y la desnutrición se mostró a partir de 1885 como un lente muy provechoso para conceptualizar los desarreglos neuróticos, era natural que por esos años emergieran líneas de resonancia o parentescos entre la literatura sobre enfermedades nerviosas y aquella sobre trastornos digestivos, particularmente la dispepsia. Por ejemplo, en la tesis que en 1891 Gofredo Paladini elaboró acerca de esta afección, hallamos una clara toma en consideración de ese terreno común:

16 Tampoco podemos pasar por alto que el perfil del dispéptico trazado por Gallastegui se condice mucho con el retrato del neurótico o del insomne de la literatura médica de esos años. Sin ir más lejos, el autor de la tesis de 1885 concluye su trabajo confesando que él ha padecido siempre de dispepsia (Gallastegui 63). En otra breve tesis defendida ese mismo año, el único historial clínico citado corresponde al de "un distinguido médico" de la Facultad, que desde hacía un año venía utilizando, a modo de método curativo contra su dispepsia, la ingesta de agua tibia antes de las comidas (J. Martínez 30). En su tesis sobre la jaqueca, redactada en 1887, Belisario Echenique comenta que hacía quince años se hallaba bajo el imperio de esa patología (Echenique 7). A resultas de ello, esas páginas contienen el análisis minucioso de su propia sintomatología (Echenique 58-59). 
No debería ser así hoy en que el refinamiento de la civilización a fuerza de incentivos que hagan más llevadera la vida, nos desvía cada vez más de las verdaderas fuentes de nuestra salud, la actividad casi febril de la vida moderna nos conduce a sacudidas en el orden psíquico [;] de aquí (...), perturbaciones en la elaboración de los materiales alimenticios; marchando esto en perfecto paralelismo con el desorden, la intemperancia y las numerosas y nocivas adulteraciones del mercantilismo moderno en los ingesta. (Paladini 11-12)

Aquel paralelismo tomó la forma de una abierta homologación en esa tesis de 1891, en la cual se proponía, a contrapelo de trabajos anteriores, una interpretación nerviosa y no química de la dispepsia. Según Paladini, ese trastorno resultaba de accidentes en el plexo nervioso abdominal, y por ese motivo se mostraba tan dependiente de la salud emocional o psíquica del sujeto. Más aún, en su propuesta de conceder atención no solo a los síntomas físicos (estagnación alimentaria, dolor, meteorismo, etc.) sino también a los psíquicos, por momentos resultaba difícil distinguir entre la sintomatología de la dispepsia y la de la neurosis (Paladini 53). La agrupación sintomática que por entonces solía caracterizar a la neurastenia (embotamiento psíquico, cansancio, insomnio y jaqueca), era tomada por Paladini como el retrato frecuente de la afección estomacal. En tal sentido, a sus ojos existía una suerte de círculo vicioso entre el neurosismo y el desarreglo digestivo (Paladini 100-101). Esa suerte de indiferenciación queda reflejada de modo transparente en los historiales clínicos que el autor desglosa en su extenso trabajo. En todos ellos se trata de hombres adultos, carentes de antecedentes hereditarios, y muchas veces pertenecientes a círculos profesionales. Casi todos ellos sufren de un conglomerado de molestias, donde el malestar gástrico tiene el mismo relieve que las contrariedades de la esfera emocional (depresión intelectual, falta de atención, humor lúgubre). Citemos uno de esos casos:

N. P., oficial del ejército, argentino, de 26 años, antecedentes hereditarios e individuales buenos, hace un año entró al hospital militar quejándose de alteraciones digestivas (...) No le molestaban tanto sus padecimientos del lado del estómago, pero le preocupaba aún más cierto grado de obnubilación intelectual (...) Sus facultades iban aminorando día a día de una manera sensible y él se abatía puesto que ni su vida arreglada, ni otras causas podían explicarle estos hechos. (...) Hoy todo le aburre, le fastidia y temiendo por sus facultades se decide a ingresar al Hospital (...). Se une a la depresión intelectual y moral la inactividad e impotencia física (...). Acusa 
desde hace varios meses pérdidas seminales con cierta frecuencia, e insomnio casi constante. (Paladini 146-147)

Esta última fuente interesa, por un lado, por la confirmación que presta a la juntura que por entonces podía establecerse entre los tópicos de lo nervioso y del debilitamiento, merced a la cual el lenguaje de las patologías digestivas podía avanzar con tranquilidad en el terreno del estudio de la fenomenología neurótica. Por otro lado, un interés complementario reside en el modo en que corrobora aquello que otras fuentes evidencian de manera quizá menos enfática: tanto por los rasgos de los dispositivos asistenciales dedicados a visibilizar las patologías nerviosas, como por la esencia de la armadura conceptual que buscaba explicarlas, pero también en función de una falta de especializaciones médicas - que no hacía otra cosa que destinar a la demanda neurótica una panoplia asaz diferenciada de ofertas profesionales-, los neuróticos porteños (insomnes, dispépsicos e impotentes) obtuvieron su reconocimiento en dispositivos enunciativos y clínicos que no se inscribían en ninguna de las sendas que a posteriori monopolizarán ese material clínico. Ni el manicomio ni la sala de enfermedades nerviosas alentó u organizó el grueso de los ensayos teóricos o prácticos que se llevaban a cabo a propósito de las nuevas entidades patológicas. Médicos generales, con esporádicas curiosidades por materias como la gastroenterología o la reumatología (o incluso la oftalmología, como en el caso de Roberts), podían disputar a proto-psiquiatras o proto-neurólogos un material clínico que deambulaba por la ciudad. Y fueron ellos quienes prestaron su pluma para ir delineando una figuración local de la neurosis.

Es momento de retornar a El nervosismo de Carlos Díaz, que no tuvo una gran acogida entre los médicos de Buenos Aires. El rótulo que figura en la portada de esa tesis fue apenas un nombre alternativo para esas condiciones que los profesionales se esforzaban por describir con el lenguaje versátil de lo nervioso. Fue un mote más para esos estados caracterizados por irritación, sobreexcitación, ansiedad y malestares corporales un tanto impredecibles. La tesis de Díaz tuvo el mérito, de todas maneras, de dejar asentado por vez primera y de modo claro, que se trataba de un territorio patológico enteramente ajeno a las vesanias o la locura; no solamente porque el espectro sintomático era muy distinto, sino ante todo debido a que no cabía suponer la intervención de ningún elemento ideativo o mental. Ahora bien, en sintonía con trabajos pioneros como el de Roberts, la problematización de lo nervioso no conllevaba en Díaz ningún diagnóstico sobre la ciudad moderna o los costos de su tecnificación. Neurosis, neurastenia o nervosidad no eran todavía sinónimos de cosmopolitismo desenfrenado. 
La agencia de producción de la esquiva enfermedad no era aún el hábitat humano, sino un cuerpo algo imaginario. Reacio a hablar de causas, Díaz atribuye a un malfuncionamiento del "Gran simpático" el punto de partida del nervosismo (Díaz 20). En otras palabras, un desequilibrio en el sistema regulador del flujo sanguíneo (del cerebro, la médula o los nervios) sería el fundamento de esa condición nerviosa. A tono con el vocabulario empleado luego por Torino, lo que vemos aquí es que lo neurótico es un estado de debilitamiento que debe ser reconducido a un desarreglo sanguíneo o circulatorio. ${ }^{17} \mathrm{~A}$ diferencia de lo que sucedió en otros contextos como el alemán, donde desde un comienzo el modelo energetista o eléctrico sirvió para describir los desarreglos nerviosos, en la medicina de Buenos Aires funcionó un prisma más bien nutricional (Roelcke). El lenguaje de los cables, los electrodos o las pilas, no aportó en estas latitudes, al menos antes del cambio de siglo, las metáforas con que describir el destino del cerebro, los nervios o los músculos. Antes del primado de ese modelo eléctricocerebral, lo que reinó fue un vocabulario del corazón y la sangre, menos plagado de tecnicismos y más próximo a las figuras y argumentos de un vitalismo difícil de remover. ${ }^{18}$ Esta aproximación entre nervosidad y debilitamiento dejaba abierta la puerta para la presunción de que las mujeres serían las víctimas frecuentes de la patología (Díaz 24). A la hora de conjeturar qué factores podían conducir a aquel debilitamiento, la pluma de Díaz reconocía el accionar de los modos de vida, pero allí se aglutinaban elementos tradicionales ligados a las pasiones y la higiene (una educación permisiva, lectura prematura de novelas, imaginación

17 De esa inspiración participa asimismo el trabajo de Ernesto de Tezanos Pinto (1887) acerca de las trofo-neurosis, es decir, de las afecciones que responden a un mal funcionamiento en la nutrición de los órganos, debida a una alteración del sistema vaso-motor dependiente del sistema nervioso. A tal respecto, vale recuperar un temprano artículo de Federico Texo publicado en la Revista Argentina de Ciencias Médicas. Se trataba de un individuo de 15 años, que desde hacía algunas semanas, y tras el esfuerzo realizado para defecar, perdió el movimiento de una mitad de su cuerpo. El examen de sus síntomas motores y sensitivos hizo presumir la existencia de una lesión focal en la médula. La causa de esa lesión era, según la deducción de Texo, un desarreglo circulatorio producido por el exceso de masturbación (Texo 359). No carece de interés remarcar que en esas fechas, en simultáneo a la difusión del lenguaje de las neurosis en las páginas médicas, comienza a extenderse el estudio de los hábitos sexuales, sobre todo la masturbación. Por el momento uno y otro fenómeno van por carriles separados. Un año atrás, Arturo Billinghurst había publicado un breve informe acerca de una joven de 23 años que presentaba un signo enigmático: a pesar de varias intervenciones del médico, una pequeña herida en una pierna se resistía a cicatrizar. Tras comprobar su estado de debilitamiento, fatiga y nerviosidad, el doctor interrogó a la paciente y logró que confesara su práctica onanista (indudable causa de la mala cicatrización, según habían demostrado algunos tratados franceses). Siguiendo la prescripción del facultativo, la muchacha abandonó su conducta pecaminosa y se estableció en el campo, tras lo cual su salud mejoró de manera significativa (Billinghurst). 
desbocada, efervescencia política, decepciones amorosas, etc.), a los que se reconocía igual poder de acción que al embarazo o la menstruación. A tono con una medicina antropológica gestada a comienzos del siglo XIX, esa condena de ciertos maneras de relacionarse con las cosas se fundamentaba más en el tópico higienista del régimen que en metáforas energetistas del desgaste (Díaz 27-28).

Al igual que el "neuro-asténico" de Roberts, el de Díaz también es un sujeto cuyo padecimiento se confunde con la conciencia de su degradación física (Díaz 48). El parecido entre estos autores no se detiene allí. Lo que garantiza la posibilidad de aglutinar estas primeras monografías (incluyendo asimismo la de Torino) es la mixtura de dos elementos negativos, que cobran singular relieve en los tres doctores más allá de sus evidentes diferencias a la hora de teorizar la enfermedad. El primero de ellos tiene que ver con la existencia de un paciente tácito, por no decir ausente. A pesar de que a lo largo de sus casi 100 páginas Díaz promete en más de una oportunidad el análisis de un caso clínico, ese presunto enfermo jamás aparece. Lo mismo sucede en la publicación de Inocencio Torino. Esa ausencia es ratificada por el texto de Roberts: a los fines de ser reconocido como neurótico, L. S. tuvo que hacer (y luego desandar) una larga travesía a través del Océano. Esos tres profesionales parecen decir a coro que en Buenos Aires no hay todavía neuróticos reales.

El segundo punto negativo tiene que ver con la paradoja de una afección sin terapia. En tanto que Torino descartaba la posibilidad de una cura, Roberts se contentaba con celebrar que allende el Atlántico esa sanación fuera posible; Díaz, a su turno, no planteaba indicaciones más precisas para el incierto neurótico de la medicina porteña. En las pocas páginas dedicadas al tratamiento, un énfasis en el valor de la profilaxis (centrada en una correcta educación infantil) era asociado a un listado incontrolado de todos los remedios posibles: distracciones, el matrimonio, estadías en el campo, viajes, drogas (ferruginosos, tónicos, sulfato de quinina, bromuro de alcanfor, belladona), hidroterapia, electroterapia, inhalaciones de oxígeno, consumo de leche. El acopio desordenado de todas las terapias, efectuado por un médico que no había tratado ningún paciente, era casi lo mismo que la negación de toda terapéutica.

Más allá de los deslizamientos o desbordes hacia un marco alternativo (la promesa de una terapéutica algo utópica en Roberts, o la señalización del talante cuasi-patológico de la afección en Díaz), lo que prima a lo largo de casi toda la década de 1880 es una representación problemática de las neurosis. Enfermedad de límites borrosos o dilatados, ella parece servir simplemente como figura aglutinadora de tres tópicos ampliamente extendidos en la mentalidad finisecular: la locura, la debilidad y la degeneración. Carente de autonomía mórbida, la neurosis parece señalar una condición que en muchos doctores (Ramos y 
Torino) no puede desmarcarse del paradigma alienista del delirio. El prisma de la locura gozaba por entonces de un real vigor, asegurado por la existencia de un dispositivo asistencial ya reconocido y valorado: el manicomio. Continuando la visión sesgada de Ramos Mejía, otros colegas no podían apropiarse de esa nueva figura sin deletrearla con el lenguaje ya compartido de la peligrosidad y la creencia errada. ${ }^{19}$ Comparte esa suerte con otras afecciones que se resisten, por el momento sin demasiado éxito, a ser colocadas en el molde errado del delirio. En efecto, por esos mismos años, la histeria atraviesa un sendero igual de escarpado, tal y como ya ha sido documentado (Vallejo). Si bien ella irrumpe más tempranamente en los recuentos estadísticos de los hospitales locales, o incluso en relatos clínicos algo extensos, la histeria carece, más o menos hasta 1886, de una autonomía mórbida irreversible. O bien nombra apenas un accidente más en un derrotero mórbido signado por la agitación y la debilidad -es lo que sucede con el caso clínico prínceps descrito por Lucilo del Castillo (1877)-; o bien lo histérico es simplemente un modo de cualificar los síntomas que aparecen descritos como epifenómenos de un delirio subyacente (Arce; Meléndez, "Locura histérica"; Ramos Mejía, "La familia"; Coni; A. Piñero,).

Por el momento el vocablo neurosis habita mayormente en las páginas de una literatura médica que busca alertar sobre la peligrosa existencia de un mal que resulta invisible para el ojo no entrenado; no obstante, el término

19 Por otro lado, entre los alienistas del período era habitual el empleo del término neurosis como sinónimo de vesania. De todas maneras, es de notar que apelaban a él muchas veces para describir casos fronterizos, donde el elemento delirante no tenía los rasgos propios de la locura inveterada, y donde el estado de locura se debía claramente a un debilitamiento orgánico. Por ejemplo, Osvaldo Eguía recurre a la categoría de neurosis al describir un caso de "pseudo locura paralítica"; se trataba de una mujer que, tras un intenso episodio de debilidad y aflicción, había caído en un estado de postración, delirio y abatimiento, del cual se curó íntegramente gracias a un tratamiento reconstituyente ferruginoso, capaz de revertir su anemia (Eguía). ¿No sería acaso correcto conjeturar que, siguiendo una práctica que ha sido documentada en diplomados europeos de esos años, Lucio Meléndez prefirió el diagnóstico de neurosis (y no el de locura) en pacientes de buen pasar económico? Podemos citar, a modo de prueba, el caso de un joven de 17 años, de buena familia, cuya melancolía apática se mostró curable gracias a un tratamiento farmacológico (Meléndez, "Melancolía"). O también la niña de trece años de edad, que vivía atormentada por una fobia al fuego e incluso al calor, que la obligaba a permanecer en cama completamente desnuda, cubierta por apenas una sábana a pesar del frío (una "neurosis parcial o monodelirio" al decir del médico). Meléndez la trató en su domicilio, y no en el asilo, y prescribió un tratamiento a base de tónicos reconstituyentes, baños fríos, equitación "y todas aquellas distracciones que pudieran hacer olvidar a la enferma su terror" (Meléndez, "Pirofobia" 85) Existe, en otro orden de cosas, un único escrito del alienista acerca de nuestro tópico, titulado "Neurosis de los atorantes $\{$ sic\}", donde el autor se concentra, en términos genéricos, en la existencia de individuos sin hogar, que se entregan al alcohol, y que se pasan la vida intentando en vano renunciar a ese hábito malsano (Meléndez, "Neurosis"). 
rara vez es empleado en los informes clínicos o las estadísticas de los centros asistenciales. Contamos con escasos registros de ese tenor, pero los pocos existentes arrojan evidencias que no pueden ser desestimadas. Por ejemplo, en el cuadro acerca de los 206 pacientes atendidos durante 1884 en el "Consultorio de enfermedades nerviosas" del Círculo Médico Argentino, no aparece ningún diagnóstico de 'neurastenia', 'nerviosismo' ni nada que se le parezca (Caballero); sin embargo, lo interesante es que ya para esa fecha, el diagnóstico de histeria era muy frecuente; sin ir más lejos, fue el más prevalente durante ese año, con 54 casos. Ello indica, a todas luces, que la patología histérica, que no recibía en la literatura teórica definiciones demasiado claras, ya tenía ganado su espacio en la práctica clínica. ${ }^{20} \mathrm{En}$ un informe sobre las actuaciones de ese consultorio en 1891 -no existen registros sobre otros períodos-, vemos que la neurastenia, en cambio, ya figuraba como un diagnóstico posible, en solo dos casos (Pacheco).

Si la elucubración sobre la neurosis no establece un diálogo ostensible con la tarea diagnóstica de los doctores practicantes, sí lo hace con las representaciones que acerca de ese mismo mal circulan durante esa década en la literatura naturalista. En efecto, en esas novelas pioneras el mote de neurosis adolece de las mismas ambigüedades, aunque no por ello deja de tener la virtud de garantizar la soldadura entre peligrosidad, simulación, delirio y degradación hereditaria. Para comprobarlo bastaría observar de qué manera el término fue empleado por el médico Manuel Podestá en su obra Irresponsable, editada en 1889. Junto con algunos personajes previos de Cambaceres, el protagonista central de aquella ficción, el enigmático hombre de los imanes, se transformó para el imaginario de aquel entonces en un típico representante del mal neurótico. ${ }^{21}$ Más aún, el triste héroe de Irresponsable encarna de modo fiel las caracterizaciones esbozadas por Ramos, Torino y Díaz. Su endeblez mórbida, sus extravagancias,

20 En un artículo arriba mencionado, se ha señalado que desde la década anterior el diagnóstico de histeria, muchas veces bajo la forma de 'histero-manía', ya era utilizado con frecuencia en otros hospitales de la ciudad (Vallejo).

21 Tal y como ha enfatizado Graciela Salto, un rasgo distintivo del neurótico de Podestá, que lo aleja de los personajes de anteriores ficciones naturalistas, reside en el hecho de que el hombre de los imanes no es "un intruso en el orden de la elite", sino un miembro natural de esos sectores que pasaron por el Colegio Nacional, los salones y las aulas de la Facultad de Medicina (Salto 95). Podríamos ver en ese detalle, por lo tanto, otra de las razones por la cual su perfil sintetiza las argumentaciones contemporáneas de lo neurótico: en los pocos casos en que el neurótico tiene rostro en la literatura médica (recordemos el paciente viajero de Roberts, el insomne Achával, el dispépsico Gallastegui o el lector al que Ramos se dirige en el cierre de su capítulo sobre las pequeñas neurosis), él pertenece a un estrato social muy distinto al de los locos y alcohólicos que llenaban las estadísticas del manicomio de Meléndez. 
su pusilanimidad, sus eternas cavilaciones inútiles ("caído en el marasmo del abandono, suicidándose poco a poco tal vez por la anemia de un cerebro que funciona con un solo objetivo, con una sola aspiración: no hacer nada, ser inútil"" [Podestá 217]); todos esos signos traducían su "sistema nervioso de neurótico" (Podestá 220), propio de esos "seres enfermos, organismos morales truncos, que van esparciendo, como la mala semilla, el germen insano de una existencia peligrosa, que lleva de una generación a otra su marca indeleble" (Podestá 282). No cabía sino un desenlace para esa afección: debido a su crisis delirante y convulsiva, termina sus días en un manicomio. Uno de los fragmentos finales de la novela parece sancionar la verdad última de la representación de neurosis que había regido las cavilaciones de tantos médicos de aquella década: "Ser transformado sucesivamente por la neurosis, por el alcohol, por la mancha hereditaria, que fue agrandándose con los años hasta eclipsar su personalidad" (Podestá 363). La neurosis era el nombre de apenas una modulación, una fase o una cara de una pendiente degradante y enfermiza, que tenía la virtud de otorgar una frágil entidad patológica a una condición donde el delirio aparece en su ausencia, donde la locura figura sobre todo como augurio infalible.

Pero al mismo tiempo, si el hombre de los imanes era la simbolización más prístina de aquella temprana y duradera caracterización del neurótico, también se convirtió de inmediato en la víctima del desencanto que esa figuración podía generar en varios actores del mundo intelectual o sanitario. A tal respecto conviene recuperar la polémica que el abogado Norberto Piñero, futuro entusiasta de la psicología experimental, entabló con Podestá desde las páginas de La Nación unas semanas después de la aparición de la novela (Salto). Si bien el intercambio giró ante todo alrededor de las insuficiencias de las tesis organicistas y deterministas utilizadas por Podestá (quien seguía esencialmente a Lombroso), uno de los principales reparos que opuso Piñero fue que el héroe de la novela, con su misteriosa mezcla de inacción y raciocinio, era "un tipo único", "literariamente verosímil" pero imposible de ser explicado mediante ninguna de las tesis desplegadas en la narración. En su última intervención, el hermano de Antonio Piñero agregaba:

El Hombre de los imanes no era un loco ni un imbécil; era un desequilibrado; y no me parece que las extrañas y equivocadas impresiones producidas -a veces, no siempre- en él por los fenómenos del mundo externo demuestren que el resultado lógico de sus múltiples factores sea la evolución que ha seguido. ( $\mathrm{N}$. Piñero) 
Las reacciones adversas suscitadas por la novela de Podestá dejan ver que hacia el cambio de década algunas voces del escenario cultural exigían para la neurosis una localización más nítida, que la rescatara de su confusión con la locura o que permitiera su autonomización mórbida. ${ }^{22}$

\section{NUEVAS FIGURACIONES}

Casi de modo simultáneo, en otras producciones teóricas comenzó a tomar forma una particular soldadura, que no denotaba en verdad otra cosa que la implantación local de una nueva figuración de lo neurótico. Nos referimos a la presunción de que la vida moderna, sobre todo en las grandes ciudades, era el fundamento necesario de esos incómodos desarreglos nerviosos. A primera vista podrá parecer que allí no hubo un gran desplazamiento en las ideas. Desde antaño, y sacando provecho de la indisoluble imposibilidad de hallar basamentos orgánicos para las enfermedades mentales o afectivas, habíanse desarrollado argumentaciones sobre el carácter deletéreo de elementos que, para hablar en términos generales, pertenecían al universo del hábitat humano y su componente afectivo. Desde fines del siglo XVIII, ante todo gracias al impulso dado a esa doctrina por Pinel, se atribuyó a las pasiones (la cólera, los celos, el afán de lucro, la religiosidad, etc.) la provocación, o el desencadenamiento, de las afecciones mentales más conocidas (Weiner). Similar poder patológico se adjudicó a otros factores emparentados, como la imaginación, el agotamiento intelectual o las conmociones políticas.

En el contexto local, Samuel Gache fue el partidario más entusiasta de esa denuncia de los poderes patógenos de todo ese conjunto de elementos que a fin de cuentas hacían al carril civilizatorio. Así, en una conferencia acerca del suicidio, dictada el 17 de mayo de 1884 ante los miembros del Círculo Médico Argentino, afirmó que "la frecuencia de este fenómeno está en razón directa al grado de civilización de las naciones" (Gache, "Patogenia" 559). De acuerdo con el médico porteño, las estadísticas disponibles indicaban que la muerte voluntaria tenía lugar de modo más frecuente "en aquellos países donde las ciencias, las manufacturas, las artes, las industrias, la política, el comercio en sus numerosos ramos, constituyen los medios habituales de la vida" (Gache, "Patogenia" 559). 
Recordemos, un poco entre paréntesis, que en algunos de sus escritos, Meléndez se había mostrado más conciliador: "no, la civilización bien entendida y tomada en su justo valor nunca daña; lo que seguramente trastorna la mente es el abuso, que no puede compararse jamás con la civilización bien entendida" (Meléndez, "Piro-terapia" 156).

Ahora bien, durante el último cuarto del siglo XIX, y comenzando con esa nueva afección llamada neurastenia, esa tradición sufrió una torsión muy clara. El énfasis empezó a ser colocado en elementos que parecían identificar la vida de las ciudades tecnificadas e inquietas: sobreabundancia de estímulos, aceleramiento, falta de tiempo, sobreexigencia intelectual. Por otro lado, esos procesos presuntamente insalubres fueron retraducidos mediante un tamiz del desgaste, que en muchos contextos, a diferencia de lo que sucedió en Buenos Aires, facilitó una reinterpretación eléctrica del funcionamiento nervioso.

Ese corrimiento puede ser notado en publicaciones porteñas apenas posteriores a los textos de Díaz o de Torino. Ya a mediados de 1886, los Anales del Círculo Médico Argentino publicaron, en dos entregas, un trabajo original del médico uruguayo Federico Susviela Guarch, que por entonces residía en Berlín. Bajo el título de "Nerviosidad", el artículo reconocía en aquel estado patológico uno de los efectos más lamentables de las condiciones de vida de las metrópolis modernas ("La nerviosidad es un fenómeno concomitante de la cultura de los pueblos actuales y de la excesiva tensión de sus fuerzas físico-morales en los combates que el espíritu libra por la vida material e intelectual" [Susviela Guarch 373]). En esas consideraciones no estaba ausente, por supuesto, el tópico del debilitamiento, en clave sanguínea, del sistema nervioso. De hecho, la problemática a tratar debía ser dividida, según el célebre médico oriental, en dos frentes: la nutrición (sanguínea) de la materia nerviosa, y "la acumulación de aquella fuerza y gasto de la misma". La modernidad atentaba, según el doctor, contra ambas dimensiones:

En nuestra época ha pasado el tiempo para la aplicación primitiva del hombre, quien en vez de labrar el campo, de perseguir la caza y la pesca, en comunidad constante con la naturaleza libre, debe pasar la vida obligado por la civilización de hoy, en el bufete de estudio, en el escritorio, o en las salas de la fábrica y del taller.

La carestía trae consigo la imposibilidad de adquirir los primeros alimentos como la carne y la sustitución de los mismos por el café, el té y el alcohol. (Susviela Guarch 375)

En lo que atañe a la economía y al gasto de esa fuerza, las grandes urbes ejercían su gesta destructiva, por ejemplo, alterando el sueño, o incluso toda forma 
de descanso, debido a la "excitación y sobreexcitación permanente de la vida de las grandes ciudades, con su caza hacia la adquisición de dinero y placeres" (374). Esta desarmonía daba lugar a un circuito difícil de interrumpir, pues el cerebro cansado, mal nutrido, no busca su bienestar sino en la sobre estimulación, para lo cual la ciudad le ofrece música, vinos, drogas (opio y morfina), tragedias y comedias, al igual que especulaciones en la bolsa y agitaciones políticas. Consecuencia de esa vida es, prosigue Guarch, la neurastenia, esa enfermedad que Beard erróneamente restringió a los Estados Unidos, y que en verdad ya se apodera de los habitantes de Europa.

Esas ideas lograron una rápida difusión entre los médicos porteños, sobre todo entre aquellos que comenzaron a utilizar asiduamente el diagnóstico de neurastenia en su clínica cotidiana. A tal respecto, cabe subrayar la buena acogida que logró la voz de Lucas Ayarragaray entre sus colegas inmediatos. Sus planteos acerca de los factores etiológicos inmateriales de la locura y el desequilibrio nervioso, fueron insistentemente recuperados por los doctores de Buenos Aires durante el cambio de siglo. Ya en su celebrada tesis de 1887, referida al papel patogénico de la imaginación y de las pasiones, Ayarragaray había preparado el terreno para su futura empresa. A pesar de que apelaba al vetusto lenguaje de la mutua influencia entre lo físico y lo moral, y a pesar de que insistía en el viejo tópico del exceso pasional, aquella tesis producía en realidad todo el tiempo un desborde del ideario tradicional, sobre todo mediante la reconducción de esos malestares al estado excepcionalmente intranquilo de la civilización fin de siècle: "Las inquietudes que aquejan la vida moderna por las exigencias que ha creado el progreso en el cumplimiento del destino individual y colectivo, producen día a día una verdadera desvinculación entre el sistema nervioso y demás aparatos de la economía" (Ayarragaray, La imaginación 10). ${ }^{23}$ En el marco de esas ideas, el neurosismo aparecía como un ejemplo ilustrativo de los efectos enervantes de las ciudades modernas (Ayarragaray, La imaginación 82).

Ahora bien, no deja de ser sintomático que esa última entidad nosológica irrumpiera en esta tesis recién en su tramo final, en el capítulo referido a la pasión amorosa. Más que leer esa particular combinación entre lo neurótico y

Hay que subrayar asimismo que esta tesis de 1887 efectuaba un segundo desmarcamiento respecto del paradigma de las pasiones, pues en esas páginas queda esbozado por vez primera en la literatura médica porteña el argumento, que reconocía en Charcot su artífice principal, según el cual la influencia de lo mental en la provocación de enfermedades se operaba a través de mediaciones más precisas que las vagas pasiones o emociones. Una idea recortada, o una representación psíquica, era capaz de producir todo un mecanismo patológico, auto-hipnosis mediante. Ese razonamiento sería reutilizado unos años después por varios doctores de Buenos Aires en sus trabajos a propósito de la enfermedad histérica (Vallejo). 
lo amoroso como un anticipo de la ligazón que lentamente se irá construyendo entre la sexualidad y esas afecciones, cabe más bien interpretarla como un indicio del momento transicional en que esas páginas quedan colocadas. La neurosis no llega a ser en la tesis de Ayarragaray una patología autónoma; es, por el contrario, apenas un epifenómeno del poder de lo psíquico sobre el organismo. Más aún, esa indeterminación mórbida es consecuente con otro rasgo de la tesis. Al igual que en los trabajos previos de la década de 1880, en las páginas de 1887 la terapéutica casi brilla por su ausencia. En este caso esa falta quizá pueda ser justificada en base al hecho de que estamos ante un trabajo más bien teórico, que aborda un tópico no reductible a una entidad mórbida particular; pero aún así, no podemos evitar poner en continuidad las escasas tres páginas que Ayarragaray dedica al abordaje curativo (en donde la medicina moral o "psico-terapéutica" tiene garantizada su lugar) con una desestimación igual de enfática asumida por los otros autores que no llegaban a reconocer en la neurosis una enfermedad de perfil nítidamente delineado.

Dos años más tarde, el médico porteño volvió a tratar el asunto en una conferencia titulada Causas sociales del neurosismo contemporáneo. Allí no hizo otra cosa que desplegar con mayor precisión el diagnóstico planteado en su tesis, insistiendo sobre todo en la conjetura según la cual el medio social actual, responsable de la enervación nerviosa tan extendida, se asentaba en una rotura de las jerarquías y estratificaciones que durante largo tiempo habían marcado el destino de los hombres. Aquella rotura dio rienda suelta a la ambición, al anhelo de forjarse cada uno su destino y su surco vital, con lo cual los organismos muchas veces sobreexigieron sus capacidades innatas ("Abierto el campo a todas las actividades y a todas las ambiciones, pocos se conforman con su estrella y su fortuna; los horizontes ilimitados se perciben de todas las esferas y los caminos que conducen al poder, a la riqueza y a los honores están llenos de desheredados que marchan afanosos con los brazos extendidos" [Ayarragaray, "Causas" 154]). De todas maneras, ese afán por arribar a una imagen más certera del elemento social moderno no iba acompañado de un avance en la autonomización mórbida de lo que allí es tildado de neurosismo. Casi como una repetición de la tensión que contaminaba la obra inicial de Ramos Mejía, el concepto de neurosis de Ayarragaray menta, ora una condición adquirida debido a la inmersión en ese hábitat social excitante, y caracterizada por la reunión de manifestaciones molestas y difusas ("ya es la cefalgia por la erección continua de la idea, ya es la dispepsia por la inquietud y la excitación perenne; o se notan esos síntomas indefinidos, vagos y tenues que comprometen algunas o todas las partes del sistema nervioso" [Ayarragaray, "Causas" 151]); ora una enfermedad mental con todo el cortejo de delirios y alucinaciones que definen a la locura. 
El umbral que Ayarragaray no pudo franquear del todo quedó definitivamente superado meses más tarde. En noviembre de 1889 concluyó su tesis de grado Ramón Eizaga, titulada Neurastenia. Se trata, a todas luces, del primer trabajo de cierta extensión que no solamente adopta sin vacilación la denominación moderna de la enfermedad, sino que reconoce en ella una entidad independiente, caracterizada sobre todo por sus manifestaciones sintomáticas, que empero son "tan múltiples y variables" (Eizaga 11). Al igual que algunos de sus predecesores, el flamante facultativo se muestra al corriente de la literatura extranjera dedicada a la materia (sobre todo las teorías etiológicas de Beard y de Erb), y define a la afección como un trastorno funcional del sistema nervioso, carente de lesión material. Si bien manifiesta su conformidad con la fórmula patogénica de Beard, según la cual la neurastenia es el efecto de la sobreexigencia de la civilización moderna, Eizaga despliega una visión más tradicional sobre la provocación de la enfermedad, donde vuelven a darse cita las clásicas elucubraciones sobre las posibles causas de las enfermedades nerviosas: junto con la herencia, cabe atender a una mal gobernada educación de los niños (excesivos trabajos intelectuales, inyección de temores imaginarios), el onanismo, los excesos venéreos, la lectura de novelas románticas, impresiones morales, enfermedades debilitantes como el tifus o la difteria, entre otros. ${ }^{24}$ Independientemente de que no predomine aquí un diagnóstico sobre la vida moderna, lo cierto es que aquello que rige la mirada causal es la suposición de que todos esos factores operan a través de un debilitamiento o desgaste de la fuerza nerviosa.

La atención de Eizaga recae principalmente en la enumeración y estudio de los síntomas típicos de la neurastenia: fatiga, temblores, irritabilidad, mirada inquieta, trastornos intestinales, ánimo depresivo, apatía, impresionabilidad e insomnio. En opinión del autor, la enfermedad suele ser crónica. El fundamento de su moderado pesimismo es que la terapéutica solo es capaz de incidir en las manifestaciones sintomáticas; para lograr una sanación rotunda sería necesario alterar radicalmente los hábitos del paciente, y esa tarea tiende a estar condenada al fracaso (Eizaga 37).

Conocedor de los dispositivos asistenciales recomendados por Charcot y por Weir Mitchell, Eizaga pondera las ventajas y límites de los abordajes habituales (hidroterapia, electricidad, fármacos). En ese contexto el autor presenta dos observaciones clínicas. Unos siete años después del paciente viajero de Roberts, tenemos aquí los perfiles de los primeros neurasténicos autóctonos. 
El primero de ellos, M. M., un vigilante de 22 años de edad, había sido atendido a mediados de 1889 en el hospital Melchor Romero de La Plata debido a problemas intestinales y gran excitabilidad nerviosa. Los síntomas más molestos (anorexia, vómitos, constipación, ánimo depresivo, insomnio y fotofobia) establecían un claro contraste con "el aspecto físico satisfactorio del individuo" (Eizaga 55). Luego de diagnosticar una "neurastenia gástrica" (o "dispepsia nerviosa"), se instaló un tratamiento basado en dieta láctea, enemas de hidrato de cloral, lavajes de estómago y sobre todo "influencia moral" del médico, tendiente a disipar los temores hipocondríacos. Menos de dos meses después de haber ingresado al nosocomio, salió de allí completamente curado.

El segundo enfermo - no tratado en verdad por el autor-, N. N., un estudiante de 24 años, presentaba síntomas más difusos, ligados sobre todo a la esfera emocional (opresión angustiosa, memoria débil, cansancio general, insomnio). Se le encomendó un cambio en sus hábitos de vida, pero esos consejos no fueron del todo observados, y se le prescribió hierro y quinina. Cuando Eizaga redacta su tesis, el tratamiento aún no ha terminado, y su pronóstico no es seguro. Ha disminuido la fatiga, se ha resuelto el insomnio, y se ha logrado convencerlo "de la naturaleza puramente nerviosa de su afección" (Eizaga 60).

Con ese balance poco concluyente se cerraba la primera tesis local sobre la neurastenia. En la medicina de Buenos Aires, entre cuyos integrantes circulaban las ideas de Beard y de Weir Mitchell, ya se podía utilizar ese diagnóstico para nominar una afección de rasgos bien definidos, para cuya caracterización no cabía apelar de ningún modo al lenguaje del alienismo. De todas maneras, ese avance en términos de autonomización conceptual no se traducía por el momento en una alteración sustancial del material clínico o terapéutico. Los dos historiales de Eizaga, uno de los cuales ni siquiera correspondía a una observación propia -y que para colmo de males no servía como ilustración de una terapia efectiva- significaban un tímido ingreso de la neurastenia a la clínica porteña.

Un abordaje más convencido se perfila en la segunda tesis acerca del tema (y última hasta el cambio de siglo), presentada en 1892 por Alberto Tessi. En este trabajo sobresalen al menos dos elementos. Por un lado, la sorpresiva denuncia del carácter masivo o endémico de la afección; según el joven profesional, la neurastenia es un mal "tan común en la actualidad que no pecaría de exagerado si lo considerara como una enfermedad a la moda" (Tessi 11). Ese enunciado era, por cierto, una copia fiel de una proposición que Elvira Rawson de Dellepiane haría ese mismo año en su tesis: 
El neurosismo, que tanto desarrollo ha adquirido en esta época, al extremo que es raro encontrar una mujer que no sea histérica, epiléptica o neurópata, producto muchas veces de la educación, los vicios, la herencia y hasta la moda; porque no se puede ser chic si no se es exquisitamente nerviosa" (Rawson de Dellepiane 40).

Mucho antes, en 1880, Mendioros atribía a la hipocondría ese mismo talante endémico: "Esta dolencia está tan expandida hoy, que se puede decir, que no hay colección individual alguna, que no abrigue en su seno una de sus numerosas víctimas" (Mendioros 12). ¿Cómo entender que una patología que apenas unos años antes brillaba por su ausencia en los registros diagnósticos de los médicos porteños, de repente se hubiera transformado en una molesta plaga? En unos instantes afrontaremos ese interrogante. Por otro lado, a diferencia de su predecesor Eizaga, Tessi retoma el ideario que Susviela Guarch y Ayarragaray habían ayudado a divulgar en la cultura científica de la ciudad. La tesis de 1892 muestra, dicho en otros términos, un apego más firme a la fórmula canónica de Beard, mostrando al mismo tiempo su convencimiento de que la descripción social efectuada por el diplomado americano no podía ser restringida al país del norte: "Entre nosotros existen también muchas causas que predisponen al desarrollo de la irritabilidad nerviosa, debido al gran desarrollo que han tomado entre nosotros las artes, las industrias y las ciencias en un pueblo que ha llegado en el corto transcurso de tiempo a ponerse al nivel de la civilización de los grandes centros europeos" (Tessi 17). Los estímulos y las sobreexigencias que Buenos Aires impone a sus habitantes provoca en ellos una falta de energía psíquica, un "cansancio cerebral", "esa especie de agotamiento que es la esencia de la neurastenia" (Tessi 16).

No podemos dejar de señalar que, detrás de esas convicciones, palpita de todos modos una suerte de cortocircuito. En efecto, al tiempo que Tessi, consecuente con su argumentación etiológica, remarca que la terapia debe estar basada en "todos aquellos medios de que disponemos para reforzar el sistema nervioso" (Tessi 39), y al tiempo que enlista los remedios que se amoldan a ese cometido (nutrición, reposo, prohibición de bebidas alcohólicas y de trabajos intelectuales, electroterapia, hidroterapia y "tratamiento psíquico"), a la hora de presentar sus dos observaciones clínicas, las cosas suceden de otro modo (sobre todo en el segundo caso). El primer paciente, un hombre de 26 años, otrora estudiante aventajado del Colegio Nacional, padecía constipación, insomnio, palpitaciones y cansancio extremo; el tratamiento medicamentoso no surtió efecto, y se le aconsejó una estadía en su provincia natal. Los tres meses transcurridos en una casa de campo de San Juan operaron un efecto casi 
milagroso, pues logró un total restablecimiento (fruto de una tonificación). Ahora bien, la paradoja se observa en el segundo enfermo, un italiano de 25 años atendido en el Hospital de esa comunidad extranjera debido a abatimiento moral y graves síntomas digestivos. Luego de comprobar que no había lesión orgánica en su aparato intestinal, y después del empleo infructuoso de algunos fármacos, la curación se logró mediante un particular "tratamiento moral": "se le hizo creer que para su enfermedad era necesario una difícil operación, lo que bastó para que el enfermo dejara pronto de pensar en su dolencia, siendo en el día un hombre en el completo estado normal" (Tessi 45).

Estamos en presencia de una zona de múltiples desacoples. Desacople, por un lado, entre la denuncia de una plaga de neurastenia, y una literatura médica en que los casos clínicos se cuentan con los dedos de una mano. Desacople, por otro lado, entre la dimensión teórica, pergeñada por jóvenes profesionales que, deseosos de mostrarse al corriente de las novedades extranjeras, repiten prolijamente el lenguaje del desgaste, la sobreexcitación y los problemas tróficos, y la dimensión práctica, donde los remedios empleados (amenazas de operaciones, persuasiones sobre la naturaleza nerviosa de la afección) entran en cortocircuito con los preceptos teóricos recién desglosados. A ese respecto, conviene recuperar una vez más la homología con la histeria, la otra gran neurosis de fin de siglo. El análisis de los textos sobre patología histérica pone igualmente en evidencia la desconexión entre los complejos y actualizados marcos teóricos defendidos por los doctores, y los abordajes terapéuticos efectivamente llevados a cabo (Vallejo).

Recuperemos el ejemplo más ilustrativo, la tesis de Ricardo Schatz sobre las parálisis histéricas. Con ese trabajo se populariza en el discurso médico porteño la sutil explicación teórica de Charcot sobre el valor etiopatogénico de la auto-sugestión, según la cual el mecanismo formador del síntoma histérico es equivalente al del proceso que tiene lugar en la hipnosis. Según la teoría elaborada por el neurólogo francés a partir de 1885, una idea, forjada mediante auto-sugestión, podía ser la causa de una parálisis (el ejemplo más claro estaría dado por aquel hombre que, en pleno estado de shock en el instante de un accidente de tránsito, tiene la certeza de que su pierna ha sido aplastada; a resultas de esa idea incorporada a su cerebro mediante auto-sugestión, el miembro inferior, orgánicamente intacto, queda paralizado) (Sanfelippo 70-84). En palabras de Schatz, que aquí glosa al neurólogo francés: "Es en estos casos por lo general un elemento sensitivo cualquiera, dolor, pesadez, etc., consecutivo a un traumatismo o a una violencia exterior que se hace para el enfermo la ocasión de una autosugestión involuntaria, lo más a menudo inconsciente, que llega a fin de cuenta a la impotencia funcional de un miembro o de una parte de 
miembro interesado" (Schatz 32-33). En resumen, en un sujeto con un miembro paralizado cabe presumir una perversión de la "idea directriz" o la "imagen motriz" correspondiente a tal o cual movimiento o zona corporal.

Ahora bien, lo valioso de esta tesis de 1891 reside tanto más en la ilustración paradójica que sus tres historiales clínicos dan de esa teoría. La tesis contiene la reseña de tres casos, y en ninguno de ellos se procedió al aislamiento del elemento ideativo que, según la teoría defendida, debía fundamentar la parálisis en cuestión. Recuperemos, por ejemplo, el primer paciente, un francés de 21 años que había sido asistido por José Esteves. Había sido internado en el Hospital San Roque debido a su incapacidad de sostenerse sobre sus piernas, a lo cual se sumaba una anestesia en la misma zona. Unos nueve meses después del inicio de su internación, lapso durante el cual no se había notado ninguna mejoría, un Esteves hastiado le dijo que "si no caminaba era porque no quería, pues nada tenía que se lo impidiese" (Schatz 102). A la mañana siguiente, el paciente debía visitar al Ministro de Francia; una vez frente al funcionario, sintió vergüenza de tener que ser cargado en brazos, hizo un "gran esfuerzo de voluntad" y logró caminar por sus propios medios. Días más tarde dejaba el hospital en buen estado de salud.

Resulta complicado, si no imposible, establecer un nexo entre esa ilustración clínica y la conjetura sobre la auto-sugestión, sobre todo en lo que respecta a la dimensión terapéutica. En su tesis, el autor había señalado que una terapia es efectiva solo si logra incidir en la causa de la afección; por ese motivo, los remedios más poderosos para revertir una parálisis eran aquellos capaces de reforzar las imágenes motrices dañadas. Entre ellos se contaban el "ejercicio forzado" del miembro, los masajes o la electroterapia (faradización). Es irrebatible que ninguno de esos abordajes fue utilizado con el paciente de origen francés. Por el contrario, en su caso se echó mano de una sugestión destinada a fortalecer la voluntad del enfermo.

\section{CONSIDERACIONES FINALES}

Hemos intentado documentar las cambiantes significaciones que las neurosis tuvieron para los médicos porteños durante las dos últimas décadas del siglo XIX, y para ello hemos analizado un extenso corpus textual que hasta el presente no había retenido la atención de los historiadores. Hemos atendido, por un lado, a las conceptualizaciones iniciales, merced a las cuales lo neurótico, o bien aparecía confundido lisa y llanamente con la locura, o bien quedaba supeditado a problemáticas como la herencia o el organicismo. Nos detuvimos 
con particular celo en las consecuencias que puede atribuirse al hecho de que Ramos Mejía, especialista pionero en afecciones nerviosas, haya sido incapaz de atribuir a las neurosis la autonomía mórbida que por esos años le concedían sus colegas europeos. Por otro lado, recuperamos las intervenciones de aquellos médicos que de modo progresivo se preocuparon por esas dolencias, prestando especial cuidado a sus lenguajes y sus recomendaciones terapéuticas. Pusimos énfasis, en tal sentido, en el modo en que la construcción del problema de la neurosis fue inseparable del reconocimiento de un nuevo sujeto patológico, que no solamente se diferenciaba del loco (debido a la ausencia de delirio), sino que incluso aparentaba ser un individuo normal o saludable. En tercer lugar, detallamos el momento en que se difunde en la medicina de Buenos Aires la presunción según la cual era menester ubicar en ciertos rasgos de las ciudades modernas (su aceleramiento, su sobrecarga de estímulos, su artificialidad) la causa de la propagación de las neurosis.

Ahora bien, incluso en los médicos que más convencidos se mostraron respecto de la legitimidad de las enfermedades neuróticas, constatamos dos cortocircuitos o desacoples. A los fines de entender ambos desacoples (el referido a la profusión o carencia de pacientes, y el relativo a la coherencia entre la teoría y la acción clínica) conviene tomar en consideración los dispositivos asistenciales que permitían efectuar esas tareas de observación, diagnóstico y tratamiento. Las tesis revisadas, así como una parte importante de los trabajos teóricos acerca de las neurosis, resultaban de labores llevadas a cabo en hospitales públicos generales, manicomios o consultorios externos ligados al Círculo Médico Argentino. Es decir, en instituciones médicas que, o bien no presentaban las condiciones ideales para replicar las observaciones o manipulaciones adheridas a las teorías originales, o bien permanecían fuera del circuito material en que algunas condiciones hallaban su terreno de despliegue; unos párrafos más abajo indicaremos que ese circuito era el mercado de consumo.

Todavía en 1907 -cuando la consolidación de algunas salas de enfermedades nerviosas podría hacer presumir que comenzaba a facilitarse la tramitación institucional de las neurosis, y en un momento en que a nivel teórico ya habían alcanzado mayor circulación lenguajes sobre automatismos o desarreglos mentales menores- el panorama no había sufrido modificaciones sustanciales (Vezzetti, Aventuras). En la tesis médica a propósito de la neurastenia presentada ese año por Manuel Cortés, ex-practicante en los hospitales San Roque y Rawson, pervivía la vieja contradicción: a pesar de afirmar que se trataba de "una afección bastante común en la época actual” (Cortés 23), y no obstante preguntar retóricamente “¿quién no tiene en nuestra época algo de neurasténico?” (Cortés 35 ), el autor no cuenta con observaciones o casos clínicos de primera mano. En 
efecto, los tres historiales presentados en el cierre de la disertación, recuperados sobre todo para remarcar el poder curativo de la psicoterapia, provienen de la práctica de otros colegas. Al respecto, el autor apela a una explicación que da en el blanco: "Es poco frecuente ver, en la práctica hospitalaria, casos concretos de neurastenia, pues rara vez se hospitalizan estos enfermos. Algunos acuden a los consultorios de clínica o enfermedades nerviosas, pero es difícil seguir en ellos el curso de su afección" (Cortés 99).

En efecto, un conjunto variado de fuentes alternativas sugiere que, a un costado de los discursos médicos ya revisados, y muchas veces sin establecer con ellos resonancias demasiado claras, en la ciudad de Buenos Aires abundaron por esos años sujetos que o bien fueron diagnosticados como neuróticos, o bien se dieron a sí mismos esa identidad patológica. Proliferaron, asimismo, artefactos culturales y objetos de consumo que invitaban a los porteños a identificar su condición sufriente como "enfermedades nerviosas" de variado tenor. En relación a esto último, es notorio que desde inicios de la década de 1880 , y con mayor fuerza unos 10 años más tarde, la prensa general incluyó una multiplicidad de avisos publicitarios de drogas y otros productos destinados a remediar ese tipo de afecciones. Hacer un listado exhaustivo de todo ese avisaje sería una tarea que excede los objetivos de este artículo. Nos limitamos a señalar que esas fuentes indican, por un lado, que se trataba de remedios "específicos" de origen extranjero (Francia e Inglaterra sobre todo), que llegaban a las farmacias locales a través de distribuidores e importadores. Muchas veces esos productos apelaban a supuestos respaldos de autoridades médicas de ultramar; de todas formas, más allá de su presunta referencia a la ciencia médica, lo cierto es que esas publicidades alentaban abiertamente el autoconsumo. ${ }^{25}$ Sabemos, por otro lado, que se trató de un mercado exitoso; un médico señaló en un libro de 1892: "Una ojeada a los anuncios de los diarios cotidianos basta para demostrarnos esta pobreza nerviosa y sanguínea. Pululan en ellos avisos y réclames de todo género, medios reconstituyentes, fortificantes, anti-nerviosos, etc." (Marcus 30). Entre los específicos más difundidos cabe incluir, primero, aquellos que según sus publicidades valían tanto para curar enfermedades nerviosas como otras condiciones mórbidas (cólicos, gota o reumatismo, entre otras): tenemos allí la "Solución de Antipirina de Trouette" (Sud-América, 15 de junio de 1891), o la "Emulsión Defresne" de aceite

25 María José Correa ha realizado una excelente investigación de ese mercado de consumo de objetos para distintas enfermedades, particularmente para el caso de Santiago de Chile entre fines del siglo XIX y comienzos del siguiente. Las apreciaciones y conclusiones que allí se efectúan tienen gran valor para comprender el caso de Buenos Aires (Correa, "Casas"; Correa, "Electricidad"; Correa, "Brulote"; Correa, "Médicos"). 
de hígado de bacalao (El Diario, 14 de abril de 1891), y el "Hierro del Dr. Girard" (Tribuna, 2 de enero de 1893). Segundo, es menester recuperar los específicos que apuntaban directamente a una o varias enfermedades nerviosas: por ejemplo, la "Solución anti-nerviosa de Laroyenne", que era capaz de remediar la epilepsia, la histeria y las patologías nerviosas en general (Sud-América, 5 de julio de 1886), o las "Grajeas Gelineau", que además de esas afecciones, sanaban también el "nervosismo" (El Correo Español, 8 de enero de 1890). En ese mismo conjunto debemos colocar los numerosos productos que, a partir de mediados de la década de 1890, prometen la curación de la neurastenia: el "Fosfato Vital de Jacquemaire" (La Semana Médica, 2 de enero de 1896, p. XI), o la "Cerebrina", que en su versión "bromada y yodada" servía para combatir la neurastenia, la neurosis y las neuralgias rebeldes (La Semana Médica, 17 de enero de 1895, p. XXIV). Si bien tuvieron una presencia más secundaria en ese mercado, hubo otros productos que también apelaban al autoconsumo, pero que no eran sustancias farmacológicas; nos referimos a los "collares magnéticos" o amuletos que eran promocionados como remedios contra las enfermedades nerviosas desde esas mismas páginas de los diarios: algunos de los más populares fueron la "Volta-Cruz" (La Prensa, 1 de febrero de 1893), o la medalla "electro-magneto-terapéutica" de José Borsani ( $E l$ Correo Español, 24 de diciembre de 1891).

Un segundo grupo de documentos atestigua con igual solvencia que por esos años efectivamente muchos sujetos en Buenos Aires fueron tratados como "neuróticos". Todos ellos tienen que ver de un modo u otro con las tareas llevadas a cabo por doctores en los cuantiosos institutos privados o consultorios particulares que se fundaron en la ciudad durante las últimas dos décadas del siglo XIX. Tanto en las publicidades incluidas en los diarios sobre esos centros clínicos, como en los folletos promocionales que se imprimieron para divulgar sus servicios, así como en informes clínicos a propósito de curaciones realizadas allí, se deja constancia de que los diplomados realmente echaron mano de los diagnósticos de neurosis en su trabajo cotidiano (o al menos intentaron atraer a la clientela ofreciendo sanaciones contra esos desarreglos). Si prestamos atención a las publicidades, por ejemplo, vemos que los primeros centros de hidroterapia y electroterapia abiertos en la Capital, anunciaban que sus servicios profesionales podían remediar las enfermedades nerviosas (sobre todo el "histerismo"). ${ }^{26}$ De hecho, al leer distintos tipos de escritos

26 Véase la publicidad del "Centro Hidroterápico" del Dr. Solá, en los Anales del Círculo Médico Argentino, Año 3, 4, 1 de mayo de 1880, s.p; o también el aviso del "Instituto Médico Hidroterápico" del Dr. Lacroze en los Anales del Círculo Médico Argentino, Año 3, 5, 1 de junio de 1880, s.p. Ver también la propaganda del "Establecimiento Médico de Aeroterapia y Atmiatría", ubicado en 
que dan cuenta de la labor de esos centros, hallamos muchos historiales o viñetas clínicas referidos a afecciones nerviosas, como histeria, neurastenia, debilidad nerviosa o impotencia del mismo origen. Se trata, a decir verdad, de páginas que ofrecen información bastante escueta sobre esos pacientes, y que brindan muy pocas pistas acerca de los concepciones teóricas que podían estar detrás de esas acciones diagnósticas o terapéuticas. Pero aun así, son de vital importancia para constatar la lenta consolidación de un trabajo clínico con las neurosis a nivel local. ${ }^{27}$

Esos dos conjuntos de indicios (las publicidades de remedios y los documentos sobre la labor privada de los doctores) muestran algo que puede resultar obvio: por fuera de la literatura teórica de la medicina de esas dos décadas (en cuyas páginas apenas si se pueden hallar informaciones sobre unos diez neuróticos), existió un circuito material de consumo que atrajo la demanda de una cantidad infinitamente mayor de neuróticos porteños. En efecto, lo que ambos conjuntos comparten es una participación igual de decidida en la lógica mercantil. Ello es más que notorio en el caso de los remedios y productos magnéticos: de acuerdo con las publicidades que contamos sobre ellos, eran expendidos libremente en una extensa serie de locales en toda la ciudad, y diversas fuentes indican que ese mercado gozó de una excelente salud todo a lo largo del fin de siglo. Ese tenor mercantil tampoco se presta a dudas en el caso de las empresas médicas: ellas fueron promocionadas mediante avisos publicitarios que intentaban realzar el tenor apetecible de los servicios ofertados allí, y numerosas crónicas de los diarios se encargaron de realzar la comodidad y el lujo que reinaba en esas instalaciones. ${ }^{28}$

Para concluir, historiadores de otros contextos ya habían recalcado, sobre todo para el caso de la neurastenia, que los pacientes preferían canalizar su demanda de atención a través de emprendimientos privados, y por ese motivo los registros de los hospitales públicos de fines de siglo incluyen muy pocos casos

Suipacha 148, en Revista Argentina de Ciencias Médicas, 1884, 2, p. 39.

Citemos, solo a modo ilustrativo, los 3 casos de histeria femenina sanados por Ernst Aberg en 1885 en su Instituto de Gimnasia Mecánica (Aberg); sabemos, por otro lado, que unos años más tarde varios neurasténicos hallarían allí un remedio eficaz contra su dolencia (Orías). Cabe recordar los 2 casos de impotencia de origen neurasténico tratados por Ricardo Sudnik mediante la inyección de tejido testicular (al estilo Brown-Séquard), método que aplicaba desde una clínica fundada en sociedad con Miguel Ferreyra (Sudnik). Hay que referir también los dos casos de "enfermedad nerviosa" curados en el "Establecimiento médico de Aeroterapia y Atmiatría", consignados por Amenedo en su tesis (Amenedo).

28 Ver, por ejemplo, "Institutos hidroterápicos", Sud-América, 27 de julio de 1891. 
de patologías neuróticas (Kaufmann). ${ }^{29}$ De todas maneras, es menester entender que esa soldadura entre neurosis y mercado fue más lejos que esa preferencia. Era casi natural que el sujeto neurótico (generalmente de clase media, muchas veces profesional), en consonancia con uno de los elementos centrales de su definición identitaria (su libertad, su capacidad de cuidar por sí mismo) haya encontrado en el mercado, sobre todo bajo la forma del autoconsumo, una de las plataformas materiales ideales con que tramitar su condición patológica.

\section{REFERENCIAS BIBLIOGRÁFICAS}

\section{Archivos}

Legajo 5793, “José María Ramos Mejía”, Archivo de la Facultad de Medicina de la Universidad de Buenos Aires.

\section{Bibliografía}

Aberg, Ernst. Resultados del tratamiento obtenidos en el Instituto Terapéutico de Gimnasia Mecánica en los cuatro primeros meses (mayo-septiembre). Imprenta de Pablo E. Coni, 1885.

Ablard, Jonathan. Madness in Buenos Aires. Patients, Psychiatrists and the Argentine State, 1880-1983. Ohio University Press, 2008.

Achaval, Guillermo. Consideraciones sobre el sueño e insomnio. Imprenta de S. Ostwald, 1880.

Alurralde, Avelino. La jaqueca. Imprenta del Porvenir, 1881.

Amenedo, Cesáreo. La Hemospasia. Imprenta del Porvenir, 1881.

Aráoz Alfaro, Gregorio. Crónicas y estampas del pasado. El Ateneo, 1938.

Arce, Celestino. Curabilidad de la locura en el manicomio de mujeres. Imprenta y litografía La Argentina, 1881.

Ayarragaray, Lucas. La imaginación y las pasiones como causas de enfermedades. Imprenta, litografía y encuadernación de Stiller \& Laass, 1887. como ya vimos, en los consultorios de enfermedades nerviosas del Círculo Médico Argentino fueron atendidos solo dos pacientes neurasténicos durante 1891 (Pacheco), en un gabinete privado especializado en electroterapia e hipnosis, cuyos avisos publicitarios figuraban de modo sistemático en los principales diarios de la ciudad, recibieron auxilio durante 1892 nada menos que 838 neurasténicos. Este último número aparece consignado en De Rossi, "Balance clínico". 
-----. "Causas sociales del neurosismo contemporáneo". Anales del Círculo Médico Argentino, vol. 12, no. 5, mayo de 1889, pp. 150-158.

Billinghurst, Arturo. "Influencia de la masturbación sobre los traumatismos". Revista Argentina de Ciencias Médicas, vol. II, no. 2, octubre de 1884, pp. 52-55.

Caballero, José María. "Consultorio de enfermedades nerviosas". Anales del Círculo Médico Argentino, vol. VIII, no. 6, 1885, pp. 262-263.

Cantón, Eliseo. Historia de la medicina en el Río de la Plata. Desde su descubrimiento hasta nuestros días, 1512 a 1925. Biblioteca de Historia Hispano-Americana, 1928.

Coni, Emilio. "Algunas observaciones sobre la histeria grave". Revista MédicoQuirúrgica, vol. 20, no. 5, 8 de junio de 1883, pp. 80-81; vol. 20, no. 6, 23 de junio de 1883, p. 95.

Correa, María José. "Casas comerciales y boticas. Aproximaciones al desarrollo del mercado médico en el Chile urbano, 1860-1910". Revista de Historia Social y de las Mentalidades, vol. 18, no. 1, 2014, pp. 9-33. http://www.revistas.usach.cl/ojs/index.php/historiasocial/article/view/2021

-----. "Electricidad, alienismo y modernidad: The Sanden Electric Company y el cuerpo nervioso en Santiago de Chile, 1900-1910". Nuevo Mundo Mundos Nuevos, Workshops, 2014, disponible en: http://journals.openedition.org/nuevomundo/66910

-----. "Brulote disfrazado, no oblea medicinal'. El avance de los específicos en el Chile urbano del Centenario". Historia de los medicamentos. Apropiaciones e invenciones en Chile, Argentina y Perú, compilado por Yuri Carvajal y María José Correa, Ocho libros, 2016, pp. 85-108.

-----. "Médicos imaginarios al sur del mundo, 1898-1913. Publicidad médica, circulación de saber y sociedad de consumo". Historia Cultura hoy. Trece entradas desde América Latina, compilado por Víctor Brangier y M. Elisa Fernández, Prohistoria, 2018, pp. 133-156.

Cortés, Manuel. Neurastenia. La Ciencia Médica, 1907.

Dagfal, Alejandro. Entre París y Buenos Aires: La invención del psicólogo (1942-1966). Paidós, 2009.

De Rossi, Gerónimo. "Balance clínico". La Prensa, 2 de febrero de 1893

De Tezanos Pinto, Ernesto. Contribución al estudio de las trofo-neurosis en general, y en particular al de la alopecía areata. Imprenta de P. E Coni e Hijos, 1887.

De Veyga, Francisco. "Prólogo". Las neurosis de los hombres célebres en la historia argentina, de José María Ramos Mejía, Editorial científica y literaria argentina, 1927, pp. I-XLIX. 
-----. "Conferencia pronunciada por el doctor Francisco de Veyga, miembro de la Academia de Medicina”. Homenaje al doctor José María Ramos Mejía, de AA.VV., Casa Jacobo Peuser, 1940, pp. 19-104.

Del Castillo, Lucilo. Un caso raro de histerismo complicado con extraordinarios fenómenos psico-morales. Imprenta del Mercurio, 1877.

Di Liscia, María Silvia y María José Billorou. "Locura y crimen en el discurso médico-jurídico. Argentina, Territorio Nacional de La Pampa, ca. 1900". Anuario de Estudios Americanos, vol. LX, no. 2, 2003, pp. 581-606. https://doi.org/10.3989/aeamer.2003.v60.i2.159

Díaz, Carlos. El nervosismo. Imprenta de 'La Universidad' de J. N. Klingelfuss, 1883.

Domínguez, Silverio. "Diarreas nerviosas". Anales del Círculo Médico Argentino, Vol. VII, no. 4, Diciembre de 1883, pp. 195-198.

Echenique, Belisario. La jaqueca clásica. Imprenta y Estenotipia de Buffet \& Bosch, 1887.

Eguía, Osvaldo. "Pseudo-locura paralítica". Revista Médico-Quirúrgica, Vol. XXI, no. 10, 23 de agosto de 1884, pp. 153-155.

Eizaga, Ramón. Neurastenia. Imprenta de Martín Biedma, 1890.

El Correo Español. 8 de enero de 1890; 24 de diciembre de 1891.

El Diario. 14 de abril de 1891.

Franceschi, Juan Mateo. "El curanderismo en la provincia de Buenos Aires". Revista Médico-Quirúrgica, Vol 21, no. 22, febrero de 1885, pp. 348-349.

Gache, Samuel. "El estado mental de la Sociedad de Buenos Aires". Anales del Círculo Médico Argentino, Vol. IV, no. 11, agosto de 1881, pp. 557-657.

-----. "Patogenia del suicidio en Buenos Aires". Anales del Círculo Médico Argentino, vol. 7, no. 9, 1 de junio de 1884, pp. 548-572.

Gallastegui, Vicente. Enfermedades del estómago. La dispepsia. Imprenta de Pablo E. Coni, 1885.

Gijswijt-Hofstra, Marijke. "Introduction: Cultures of Neurasthenia from Beard to the First World War". Cultures of Neurasthenia. From Beard to the First World Warm compilado por Marijke Gijswijt-Hofstra y Roy Porter, Rodopi, 2001, pp. 1-30. https://doi.org/10.1163/9789004333406_002

Gijswijt-Hofstra, Marijke \& RoyPorter,eds. Cultures of Neurasthenia.FromBeardto the First World War. Rodopi, 2001. https://doi.org/10.1163/9789004333406 Groussac, Paul. Los que pasaban. Huemul, 1972 [edición original de 1919]. Kaufmann, Doris. "Neurasthenia in Wilhelmine Germany: Culture, Sexuality, and the Demands of Nature". Cultures of Neurasthenia. From Beard to the First World War, compilado por Marijke Gijswijt-Hofstra y Roy Porter, Rodopi, 2001, pp. 161-176. https://doi.org/10.1163/9789004333406_009 
Ingenieros, José. "La personalidad intelectual de Ramos Mejía (1849-1914)". Revista de Filosofia, vol. 2, 1915, pp. 103-148.

KØppe, Simo. "Neurosis: aspects of its conceptual development in the nineteenth century". History of Psychiatry, vol. 20, no. 1, 2009, pp. 20-46. https:// doi.org/10.1177/0957154x08092426

La Prensa. 1 de febrero de 1893.

La Semana Médica. 2 de enero de 1896, p. XI; 17 de enero de 1895, p. XXIV.

López Piñero, José M. Historical Origins of the Concept of Neurosis. Cambridge University Press, 2009 [edición original de 1983].

Lutz, Tom. "Varieties of Medical Experience: Doctors and Patients, Psyche and Soma in America". Cultures of Neurasthenia. From Beard to the First World War, compilado por Marijke Gijswijt-Hofstra y Roy Porter, Rodopi, 2001, pp. 51-76. https://doi.org/10.1163/9789004333406_004

Marcus, Hugo. Higiene de los nervios. Félix Lajouane, 1892.

Martínez, Lorenzo. La dispepsia. Imprenta de M. Biedma, 1879.

Martínez, José. Contribución al estudio de las dispepsias. Imprenta de 'La Universidad' de J. N. Klingelfuss, 1885.

Meléndez, Lucio. "Clínica cerebral”. Revista Médico-Quirúrgica, vol. 17, no. 4, 23 de mayo de 1880, pp. 77-81.

-----. "Piro-terapia". Revista Médico-Quirúrgica, vol. 18, no. 8, 23 de julio de 1881, pp. 156-159.

-----. "Locura histérica". Revista Médico-Quirúrgica, vol. 19, no. 5, 23 de junio de 1882, pp. 109-11, 125-126.

-----. "Neurosis de los atorantes". Revista Médico-Quirúrgica, Vol. 21, no. 7, 8 de julio de 1884, pp. 104-106.

-----. "Melancolía apática". Revista Médico-Quirúrgica, vol. 21, no. 18, 23 de diciembre de 1884, pp. 284-285.

-----. "Pirofobia". Revista Médico-Quirúrgica, vol. 22, no. 6, 23 de junio de 1885, pp. 83-85.

Meléndez, Lucio y Emilio Coni. "Estudio estadístico sobre la locura en Buenos Aires". Revista Médico-Quirúrgica, vol. 17, 1880, pp. 451-459, 484-498, 507-519.

Melo, Carlos. Neurastenia. Argos, 1896.

Memoria de la Facultad de Ciencias Médicas. Anales de la Universidad de Buenos Aires, vol. V, 1890.

Mendioros, Francisco. Ensayo sobre la hipocondría. Imprenta de M. Biedma, 1880.

Millán, Julio. "Algunos apuntes sobre la fisiología de la educación”. Anales del Círculo Médico Argentino, vol. 4, no. 2, 1880, pp. 196-208. 
Moyano, Virgilio. Consideraciones sobre la dispepsia. Establecimiento tipográfico, 1881.

Nouzeilles, Gabriela. "Hysteria in turn-of-the-century Buenos Aires". Disease in the History of Modern Latin America: From Malaria to AIDS, compilado por Diego Armus, Duke University Press, 2003, pp. 51-76. https://doi.org/10.2307/j.ctv11smx34

-----. “Asesinatos por sugestión: estética, histeria y transgresión". The Colorado Review of Hispanic Studies, 4, 2006, pp. 309-325.

Orías, Gabriel. La Gimnasia mecánica. Algunas de sus principales indicaciones terapéuticas. Imprenta Europea, 1895.

Pacheco, Román. "Consultorio de enfermedades nerviosas, y de la garganta, nariz y oídos". Anales del Círculo Médico Argentino, vol. XV, no. 3, 1892, pp. 211-214.

Paladini, Gofredo. Consideraciones sobre la dispepsia. Imprenta de Martin Biedma, 1891.

Pietikainen, Petteri. Neurosis and Modernity. The age of nervousness in Sweden. Brill, 2007. https://doi.org/10.1163/ej.9789004160750.i-391

Piñero, Antonio. "Un caso de histeria en el hombre". Revista Argentina de Ciencias Médicas, vol. III, no.1, 1886, pp. 11-23.

Piñero, Norberto. "Contra-réplica. El hombre de los imanes", La Nación, 16 de marzo de 1890.

Pita, Valeria. La casa de las locas. Una historia social del Hospital de Mujeres Dementes, Buenos Aires, 1852-1890. Prohistoria, 2012.

Plotkin, Mariano. Freud en las Pampas. Sudamericana, 2003.

Podestá, Manuel. Irresponsable. Biblioteca de 'La Nación', 1903 [edición original de 1889].

Ramos Mejía, José María. Las neurosis de los hombres célebres en la historia argentina. Editorial científica y literaria argentina, 1927 [edición original de 1878-1882].

-----. "La familia Lobato". Anales de la Asistencia Pública, vol. I, no. II, 15 de agosto de 1891, pp. 73-88.

-----. Estudios clínicos sobre las enfermedades nerviosas y mentales. Félix Lajouane, 1893.

-----. La locura en la historia. Contribución al estudio psicopatológico del fanatismo religioso y sus persecuciones. Félix Lajouane, 1895.

Rawson de Dellepiane, Elvira. Apuntes sobre higiene en la mujer. Imprenta de Pablo E. Coni, 1892.

Roberts, Pedro. "Neuro-astenia". Revista Médico-Quirúrgica, vol. 20, no. 13, 8 de noviembre de 1883, pp. 235-238; vol. 21, no. 2, 23 de abril de 1884, pp. 19-22; vol. 21, no. 4, 23 de mayo de 1884, pp. 52-57. 
Rodríguez, Julia. "The Argentine Hysteric. A Turn-of-the-century Psychiatric Type". Argentina on the Couch. Psychiatry, State and Society, 1880 to the present, compilado por Mariano Plotkin, University of New Mexico Press, 2003, pp. 25-47.

Roelcke, Volker. "Electrified Nerves, Degenerated Bodies: Medical Discourses on Neurasthenia in Germany, circa 1880-1914". Cultures of Neurasthenia. From Beard to the First World War, compilado por Marijke Gijswijt-Hofstra y Roy Porter, Rodopi, 2001, pp. 177-197. https://doi.org/10.1163/9789004333406_010

Rosenthal, Moritz. Traité clinique des maladies du système nerveux. G. Masson, 1877.

-----. Tratado clínico de las enfermedades del sistema nervioso. Imprenta de Enrique Teodoro, 1878.

Ruggiero, Kristin. Modernity in the Flesh. Medicine, Law, and Society in Turnof-the-Century Argentina. Stanford University Press, 2004.

Ruibal, Beatriz. "El honor y el delito. Buenos Aires a fines del siglo XIX". Entrepasados, vol. 11, 1996, pp. 35-44.

Salto, Graciela. "El debate científico y literario en torno de Irresponsable de Manuel T. Podestá". Anclajes. Revista del Instituto de Análisis Semiótico del Discurso, vol. II, no. 2, 1998, pp. 77-103.

Sanfelippo, Luis. Trauma. Un estudio histórico en torno a Sigmund Freud. Miño y Dávila, 2018.

Scharagrodsky, Pablo. "Entre la maternidad y la histeria. Medicina, prácticas corporales y feminidad en el Buenos Aires de fin del siglo XIX". Gobernar es ejercitar. Fragmentos históricos de la educación física en Iberoamérica, compilado por Pablo Scharagrodsky, Prometeo, 2008, pp. 105-135.

Schatz, Ricardo. Contribución al estudio de la parálisis histérica. Imprenta de Martin Biedma, 1891.

Scull, Andrew. Madness in Civilization. A cultural history of insanity from the Bible to Freud, from the madhouse to modern medicine. Princeton University Press, 2015. https://doi.org/10.2307/j.ctvc77hvc

Shorter, Edward. "Private Clinics in Central Europe, 1850-1933". Social History of Medicine, vol. 3, no. 2, 1990, pp. 159-195. https://doi.org/10.1093/ $\mathrm{shm} / 3.2 .159$

Souza, Pablo. Una 'República de las Ciencias Médicas' para el desierto argentino. El Círculo Médico Argentino y la inscripción de un programa experimental en las ciencias médicas de Buenos Aires (1875-1914). Tesis doctoral, Facultad de Filosofía y Letras, Universidad de Buenos Aires, 2014, inédita. 
Stagnaro, Juan. Lucio Meléndez y el nacimiento de la psiquiatría como especialidad médica en la Argentina (1870-1890). Tesis doctoral, Facultad de Medicina, Universidad de Buenos Aires, 2005, inédita.

Sud-América. 5 de julio de 1886; 15 de junio de 1891.

Sudnik, Ricardo. "Consideraciones generales sobre las inyecciones de BrownSecquard y la impotencia". Revista de la Sociedad Médica Argentina, vol. II, no. 11, septiembre-octubre de 1893, pp. 343-361; vol II, no. 12, noviembre-diciembre de 1893, pp. 451-471.

Susviela Guarch, Federico. "Nerviosidad. Sus causas. Modos de evitarlas". Anales del Círculo Médico Argentino, vol. IX, no. 6, junio 1886, pp. 371379; vol. IX, no. 7, julio 1886, pp. 429-437.

Tessi, Alberto. Neurastenia. Imprenta de Martín Biedma, 1892.

Texo, Federico. "Observación de un caso de hematomielia atribuido a la masturbación”. Revista Argentina de Ciencias Médicas, vol. II, no. 10, septiembre de 1885, pp. 349-360.

Torino, Inocencio. Estudio de algunas relaciones del simpático y el cerebro. Imprenta de M. Biedma, 1880.

-----. "Estado mental de A. Pagano". Anales del Círculo Médico Argentino, vol. 7, no. 3, 1884, pp. 852-878.

-----. "Las neurosis". Revista Médico-Quirúrgica, vol. 22, no. 4, 23 de mayo de 1885 , pp. 52-59.

Tribuna. 2 de enero de 1893.

Vallejo, Mauro. "Cuerpos histéricos en la medicina de Buenos Aires (1877-1900).

Teorías, representaciones y dispositivos clínicos". Revista Historia, vol. 52, no. 1, enero-junio 2019, pp. 139-167. http://dx.doi.org/10.4067/ S0717-71942019000100139

Vezzetti, Hugo. La locura en la Argentina. Folios Ediciones, 1983.

-----. Freud en Buenos Aires. Universidad de Quilmes, 1996 [edición original de 1989].

-----. Aventuras de Freud en el país de los argentinos. De José Ingenieros a Enrique Pichon-Rivière. Paidós, 1996.

Weiner, Dora. Comprender y curar. Philippe Pinel (1745-1826), la medicina de la mente. Fondo de Cultura Económica, 1999. 